OPEN ACCESS

Edited by:

Isidre Ferrer,

University of Barcelona, Spain

Reviewed by:

Nicolás Cuenca,

University of Alicante, Spain M. Francesca Cordeiro,

University College London,

United Kingdom

${ }^{*}$ Correspondence:

José M. Ramírez

ramirezs@med.ucm.es

Received: 06 April 2017

Accepted: 16 June 2017

Published: 06 July 2017

Citation:

Ramirez Al, de Hoz R,

Salobrar-Garcia E, Salazar JJ, Rojas B, Ajoy D, López-Cuenca I, Rojas P, Triviño A and Ramirez JM

(2017) The Role of Microglia in Retinal

Neurodegeneration: Alzheimer's

Disease, Parkinson, and Glaucoma.

Front. Aging Neurosci. 9:214.

doi: 10.3389/fnagi.2017.00214

\section{The Role of Microglia in Retinal Neurodegeneration: Alzheimer's Disease, Parkinson, and Glaucoma}

\author{
Ana I. Ramirez ${ }^{1,2}$, Rosa de Hoz ${ }^{1,2}$, Elena Salobrar-Garcia ${ }^{1,3}$, Juan J. Salazar ${ }^{1,2}$, \\ Blanca Rojas ${ }^{1,3}$, Daniel Ajoy ${ }^{1}$, Inés López-Cuenca ${ }^{1}$, Pilar Rojas ${ }^{1,4}$, Alberto Triviño ${ }^{1,3}$ and \\ José M. Ramírez ${ }^{1,3 *}$ \\ ${ }^{1}$ Instituto de Investigaciones Oftalmológicas Ramón Castroviejo. Universidad Complutense de Madrid, Madrid, Spain, \\ ${ }^{2}$ Departamento de Oftalmología y ORL, Facultad de Óptica y Optometría, Universidad Complutense de Madrid (UCM), \\ Madrid, Spain, ${ }^{3}$ Departamento de Oftalmología y ORL, Facultad de Medicina, Universidad Complutense de Madrid (UCM), \\ Madrid, Spain, ${ }^{4}$ Servicio de Oftalmología, Hospital Gregorio Marañón, Madrid, Spain
}

Microglia, the immunocompetent cells of the central nervous system (CNS), act as neuropathology sensors and are neuroprotective under physiological conditions. Microglia react to injury and degeneration with immune-phenotypic and morphological changes, proliferation, migration, and inflammatory cytokine production. An uncontrolled microglial response secondary to sustained CNS damage can put neuronal survival at risk due to excessive inflammation. A neuroinflammatory response is considered among the etiological factors of the major aged-related neurodegenerative diseases of the CNS, and microglial cells are key players in these neurodegenerative lesions. The retina is an extension of the brain and therefore the inflammatory response in the brain can occur in the retina. The brain and retina are affected in several neurodegenerative diseases, including Alzheimer's disease (AD), Parkinson's disease (PD), and glaucoma. $A D$ is an age-related neurodegeneration of the CNS characterized by neuronal and synaptic loss in the cerebral cortex, resulting in cognitive deficit and dementia. The extracellular deposits of beta-amyloid $(A \beta)$ and intraneuronal accumulations of hyperphosphorylated tau protein (pTau) are the hallmarks of this disease. These deposits are also found in the retina and optic nerve. PD is a neurodegenerative locomotor disorder with the progressive loss of dopaminergic neurons in the substantia nigra. This is accompanied by Lewy body inclusion composed of $\alpha$-synuclein ( $\alpha$-syn) aggregates. PD also involves retinal dopaminergic cell degeneration. Glaucoma is a multifactorial neurodegenerative disease of the optic nerve, characterized by retinal ganglion cell loss. In this pathology, deposition of $A \beta$, synuclein, and pTau has also been detected in retina. These neurodegenerative diseases share a common pathogenic mechanism, the neuroinflammation, in which microglia play an important role. Microglial activation has been reported in $A D, P D$, and glaucoma in relation to protein aggregates and degenerated neurons. The activated microglia can release pro-inflammatory cytokines 
which can aggravate and propagate neuroinflammation, thereby degenerating neurons and impairing brain as well as retinal function. The aim of the present review is to describe the contribution in retina to microglial-mediated neuroinflammation in $A D, P D$, and glaucomatous neurodegeneration.

Keywords: microglia, neuroinflammation, Alzheimer's Disease, Parkinson, glaucoma, retina, beta-amyloid, synuclein

\section{INTRODUCTION}

Alzheimer's Disease (AD) and Parkinson's Disease (PD) are the most common neurodegenerative disorders (de Lau and Breteler, 2006). AD involves progressive memory loss and dementia (Sharma and Lipincott, 2017), while the PD is a chronic and progressive movement disorder (Orr et al., 2002). Glaucoma, a neurodegenerative disease of the optic nerve, is characterized by death of retinal ganglion cells (RGCs) (de Hoz et al., 2016). Recently, neurodegenerative lesions have been detected in the intracranial optic nerve, the lateral geniculate nucleus, and the visual cortex (Gupta et al., 2006, 2007), suggesting that this pathology could be grouped as a neurodegenerative disease (Yucel et al., 2003).

$\mathrm{AD}$ is a neurodegenerative disorder related to age, in which neuronal and synaptic losses in the cerebral cortex lead to cognitive impairment, behavioral deficits and dementia (Ghiso et al., 2013). The major pathology related to $\mathrm{AD}$ is the extracellular deposit of $\beta$-amyloid $(\mathrm{A} \beta)$ in the form of parenchymal plaques and cerebral amyloid angiopathy co-existing with intraneuronal accumulations of hyperphosphorylated tau (pTau) (neurofribillary tangles) (Ghiso et al., 2013). These deposits can induce neuronal death by apoptosis (Garcia-Ospina et al., 2003). Initially, it was thought that age was the main risk factor for this disease. However, it is now known to have a multifactorial origin and it seems to result from a complex interaction of multiple environmental and genetic factors (Wostyn et al., 2010). AD has been related to genetic mutations, among them in the gene encoding the $\mathrm{A} \beta$ precursor protein peptide, mutations in the presenilins genes (Calabrese et al., 2001) and the presence of the APOE $\varepsilon 4$ allele (Martínez-Lazcano et al., 2010). In addition, AD is frequently associated with vascular dysfunctions and inflammation (Dudvarski Stankovic et al., 2016).

$\mathrm{PD}$ is characterized by the progressive loss of dopaminergic neurons in the substantia nigra pars compacta and the nerve terminals in the striatum (Dauer and Przedborski, 2003). The clinical symptoms of PD are mainly motor problems, including bradykinesia, rigidity, tremors, and postural instability. In addition, PD presents non-motor symptoms including disorganized speech and altered moods (Fakhoury, 2016). The loss of neurons is accompanied by abnormal intracytoplasmic filamentous aggregates called Lewy bodies. These aggregates (deposited in somas and axons) are constituted by $\alpha$-syn, parkin, phosphorylated neurofilament and components of the protheosomic-ubiquitin pathway (Orr et al., 2002). The main etiological factors proposed for PD are aging, environmental toxins, and genetic factors. Neurodegeneration could be due to exposure to dopaminergic neurotoxins e.g., herbicides (MPTP), insecticides (Rotenone), and metals (Hernández-Montiel, 2006). Genetic factors include mutations in $\alpha$-syn (Olanow and Tatton, 1999; Pérez and Arancibia, 2007), while mitochondrial dysfunction and oxidative stress may also act by causing the accumulation of misfolded proteins (Dauer and Przedborski, 2003).

Glaucoma is an age-related multifactorial neurodegenerative disease of the optic nerve, with an irreversible decrease in RGCs, causing a visual-field loss and cupping of the optic nerve head (Quigley et al., 1988). In glaucoma, increased intraocular pressure (IOP), vascular dysregulation, and the immune system activation can trigger several changes in retina and optic nerve including: disrupted axonal transport and neurofilament accumulation, microvascular abnormalities, extracellular matrix remodeling, and glial cell activation. These alterations can lead to secondary damage such as, excitotoxicity, neurotrophin deprivation, oxidative damage, mitochondrial dysfunction, and eventually RGC death (Nickells, 1999; Gallego et al., 2012). In addition, there is a dendritic atrophy of the lateral geniculate nucleus, the site to which the RGC axons project (Gupta et al., 2007; Park and Ou, 2013).

The AD, PD and glaucoma share certain biological features, for example: (i) they are slow and chronic neurodegenerative disorders with a strong age-related incidence; (ii) they have similar mechanisms of cell injury and deposition of protein aggregates in specific anatomical areas (Wostyn et al., 2010; Kaarniranta et al., 2011; Ghiso et al., 2013); and (iii) death occurs in one or more populations of neurons (RGCs in glaucoma, hippocampal and cortical neurons in $\mathrm{AD}$ and nigrostriatal dopaminergic neurons in PD) (Mattson, 2000). Although the exact mechanism bringing about this neuronal death remains unknown, these neurodegenerative disorders seem to have pathogenic mechanisms in common. These mechanisms include: oxidative stress (Uttara et al., 2009), mitochondrial dysfunction (Lee et al., 2011; Lascaratos et al., 2012; Chrysostomou et al., 2013), alterations in the ubiquitin-proteasome system (Campello et al., 2013), abnormal accumulation of misfolded proteins, glutamate excitotoxicity (Gazulla and Cavero-Nagore, 2006; Guimaraes et al., 2009), and glial activation and inflammation (Verkhratsky et al., 2014; Brown and Vilalta, 2015). These mechanisms could act individually or synergistically (Ghiso et al., 2013).

Inflammation is a defensive process of the body against damage that seeks to restore tissue integrity. Neuroinflammation, the inflammation of central nervous system (CNS), is essential to protect the tissue. However, uncontrolled and prolonged neuroinflammation is potentially harmful and can cause cellular 
damage. The astrocytes and microglia could play a major role in the neuroinflammation associated with neurodegenerative diseases (Cherry et al., 2014). The presence of reactive astrocytes, the microglial activation, and the release of inflammatory mediators such as cytokines, reactive oxygen species (ROS), nitric oxide (NO), and Tumor Necrosis Factor- $\alpha$ (TNF- $\alpha$ ) could cause a state of chronic inflammation that may exert neurotoxic effects (Cuenca et al., 2014).

The neuroinflammatory process occurs not only in the brain, but also in the retina, which is a projection of the CNS. The retina and brain are associated over a range of neurological and neurovascular conditions of varying etiologies, because the retina and brain are similar, and respond similarly to disease. Thus, it has been described that the retina is a "window to the brain," and the manifestation of disease in the brain is the same as in the retina (MacCormick et al., 2015). The neuroinflammatory changes could be observed using optical coherence tomography (OCT), a routinely diagnostic techniques used in ophthalmology. This technique provides anatomic detail of pathological changes in the retina and optic nerve. Changes in OCT measurements have been used to study the course of particular neurologic diseases such AD (Garcia-Martin et al., 2014; Maldonado et al., 2015; Salobrar-Garcia et al., 2015, 2016a,b), PD (Yu et al., 2014; Stemplewitz et al., 2015; Boeke et al., 2016; Satue et al., 2017), and glaucoma (Leung, 2016; Fallon et al., 2017), suggesting that the data compiled may be useful as a biomarker in diagnosing and treating neurodegenerative disease.

The aforementioned data underline the importance of knowing the function of inflammatory processes in the retina of neurodegenerative diseases (AD, PD, and glaucoma), especially the contribution to microglial-mediated neuroinflammation.

\section{MICROGLIAL ACTIVATION}

In neurodegenerative diseases, neuroinflammation constitutes a fundamental process in which microglial cells play a key role (Glass et al., 2010). Microglial cells are CNS resident immune cells which have sensor and effector functions as well as phagocytic capacity (Streit et al., 2005). In the developing of CNS these cells enter from the bloodstream, develop from monocytes, and differentiate into microglia. Thus, they maintain numerous cellular antigens present in macrophages and monocytes (Ransohoff and Cardona, 2010). Microglia express $\mathrm{CD} 11 \mathrm{~b} / \mathrm{c}, \mathrm{D} 45^{\mathrm{low}}$, and the chemokine fractalkine receptor (CX3CR1) (Dudvarski Stankovic et al., 2016). These cells survey the CNS in order to detect homeostasis alteration and they respond accordingly, combining a defensive service with neuroprotective functions (Verkhratsky and Butt, 2013).

In addition to the immune functions, microglia have an essential role in the physiology and survival of neurons. Fractalkine, involved in indirect neuroprotection, is released by neurons and the receptor is expressed by microglia, their interactions constituting a neuron-microglial signaling system (Ransohoff and El Khoury, 2015). The fractalkine expressed by neurons can induce adenosine release from microglia. This adenosine (via adenosine A1 receptor) can activate survival pathways in neurons sensitive to excitotoxicity challenge (Lauro et al., 2008, 2010). The signaling mediated by CX3CR1 could regulate microglial behavior in the neurodegenerative diseases.

The presence of protein aggregates in the CNS is a common feature of most neurodegenerative disorders. These aggregates are identified by the Toll-like receptors (TLRs) which are danger-signal sensors. Microglial cells express these receptors (TLR1-TLR9) and their co-receptors, which promote microglial activation (Gonzalez et al., 2014). Concretely, TLR4 and TLR2 are associated with both neuro-inflammation and clearance of protein aggregates in neurodegenerative disorders (Jack et al., 2005).

Microglia constitute the first line of immune defense in CNS. After injury these cells become activated and in this state change their morphology, proliferate, migrate to the damage sites, modify the expression of enzymes and receptors, and release a variety of inflammatory factors, such as NO, tumor necrosis factor (TNF- $\alpha$ ), interleukin (IL-6) among others (Magni et al., 2012). The morphology of activated microglia includes a retraction of processes, enlargement of the soma, and increased expression of myeloid cell markers (Ransohoff and Cardona, 2010). In their state of high activation, microglial cells acquire an amoeboid morphology and act like macrophages, engulfing debris (Brown and Neher, 2014). Excessive microglia activation might prompt the release of cytotoxic factors, causing neuronal damage, which could accelerate the progression of some CNS diseases.

Microglial cells may undergo two different kinds of activation in response to infections or injuries. The first is a neurotoxic phenotype called M1-like. This phenotype generates a massive

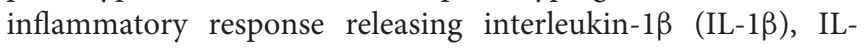
12, TNF- $\alpha$ and inducible nitric oxide synthase (iNOS). M1 microglial cells present amoeboid morphology as well as high phagocytic capacity and motility (Varnum and Ikezu, 2012; Gonzalez et al., 2014; Jones and Bouvier, 2014). However, in certain circumstances, the neuroinflammation can help stimulate myelin repair or remove toxic aggregated proteins and cell debris from CNS (Ding et al., 2004; Simard et al., 2006; Glezer et al., 2007). After this acute M1 activation, microglial cells can suffer an uncontrolled activation leading to a state of chronic inflammation. In this state, microglia release neurotoxic inflammatory factors (TNF- $\alpha$, IL- $1 \alpha$, IL- $1 \beta$, IL-6, NO, hydrogen peroxide, superoxide anion, chemokines, and glutamate), which lead to neuronal death (Block et al., 2007; Lull and Block, 2010; Burguillos et al., 2011; Kettenmann et al., 2011; Gordon et al., 2012).

The second microglial phenotype, M2-like, secrete antiinflammatory mediators and neurotrophic factors, thus inducing a supportive microenvironment for neurons (Kettenmann et al., 2011). The M2 microglial cells are characterized by thin cellular bodies and ramified processes (Menzies et al., 2010; Komori et al., 2011; Varnum and Ikezu, 2012; Jones and Bouvier, 2014; Zhou et al., 2014). These cells can release anti-inflammatory cytokines including IL-4, IL-13, IL-10, TGF- $\beta$ and neurotrophic factors, such as insulin-like growth factor 1 (IGF-1) to assist inflammation resolution and promote neuron survival (Suh et al., 2013; Tang and Le, 2016). M2 microglia are the major effector 
cells with the potential to dampen pro-inflammatory immune responses and promote the expression of repair genes (Tang and Le, 2016). The change of microglia between M1 and M2 phenotypes is a dynamic process and microglial activation can switch from M2 to M1 phenotype during the course of disease (Cherry et al., 2014).

Recently, it has been reported that microglia release extracellular microvesicles (Evs) by exocytosis. These microvesicles are involved in all immune activities and can be protective or detrimental, affecting some pathologies of the CNS. EVs have a heterogeneous molecular composition, including receptors, integrins and cytokines, bioactive lipids, miRNA, mRNA, DNA, and organelles, being similar to their parental cells. They can be detected in the plasma and other biological fluids such as the cerebral spinal fluid (CSF). The microglial EVs representing a "liquid biopsy" of their parental cells, and could provide information on the functional phenotype (protective or damaging) of microglial cells over the course of neurodegeneration (Nigro et al., 2016).

Microglia and astrocytes are the main innate immune effector cells in the CNS (da Fonseca et al., 2014). Under pathological conditions, astrocytes and microglia can collaborate to induce an inflammatory response. After injury, astrocytes produce cytokines and chemokines (CCL2, CXCL1, CXCL10, GM-CSF, and IL-6), which activate microglia and recruit peripheral immune cells to the CNS. By contrast, a recent report has described an astrocyte subtype $\mathrm{A} 1$ that is abundant in $\mathrm{AD}$ and $\mathrm{PD}$ and other human neurodegenerative diseases. Activated microglia can induce A1 astrocytes by secreting IL- $1 \alpha$, TNF, and C1q, and this type of astrocyte contribute to the death of neurons in the neurodegenerative disorders and could be analog to the M1-like phenotype microglia (Liddelow et al., 2017).

Microglia, together with endothelial cells, pericytes, and astrocytes, form the functional blood-brain barrier (BBB) that selectively separates the brain parenchyma from blood circulation. In this perivascular location, the microglia survey the influx of blood-borne components entering the CNS. The activated microglia can induce the dysfunction of the $\mathrm{BBB}$, being correlated with the disruption of the $\mathrm{BBB}$ in the neurodegenerative diseases (Dudvarski Stankovic et al., 2016). During inflammatory conditions, innate immune cells (DCs, neutrophils, monocytes, and natural killer cells) and adaptive immune cells (activated B cells together with CD4+ and CD8+ T cells) are recruited by chemoattractants to cross the BBB from the periphery. The presence of this cellular infiltrate in the CNS can directly or indirectly provoke neuroinflammation by producing pro-inflammatory cytokines/chemokines. All this could generate oxidative stress, which leads to neuronal death. In addition, activated microglia are capable of upregulating CD11c, MHC I, and MHC II to act as antigen-presenting cells, which activate T cells. This activation would in turn damage the nervous system (Xu et al., 2016).

As mentioned above, during the inflammatory process, there is a are released of cytokines. Cytokines bind to receptors in the microglia and activate the JAK/STAT signaling pathway (Yan et al., 2016). This pathway plays a critical role in the initiation and regulation of innate immune responses and adaptive immunity
(Yan et al., 2016). Although the same JAK/STAT components are used, the gene expression in response to a specific cytokine, depending on the cell type (van Boxel-Dezaire et al., 2006). This pathway constitutes a pattern-recognition system by which microglial cells respond to foreign antigens and inflammation in the CNS (Hanisch and Kettenmann, 2007).

In microglial cells, other receptors called the "triggeringreceptors-expressed-on-myeloid-cells" (TREM) are thought to play a central role in the immune-system regulation and inflammation. The signaling pathway TREM2 regulates apoptosis, the immune response, and phagocytic activity. Brain homeostasis without inflammation depends on eliminating extracellular aggregates and apoptotic debris, this being mediated by the TREM2/DAP12 receptor complex (Han et al., 2017). The signaling pathway TREM2 regulates the apoptosis, the immune response, and the phagocytic activity. This pathway, induced in the microglial cells by anti-inflammatory cytokines, is modulated by CD33 and is down-regulated by agonists of TLR2, 4, and 9 , as well as by inflammatory stimuli such as lipopolysaccharides and RNA interference. An overexpression of TREM2 promotes phagocytosis and reduces the pro-inflammatory response (Han et al., 2017). This receptor is a critical regulator of microglia and macrophage phenotype and is involved in neurodegenerative diseases (Andreasson et al., 2016).

After damage, microglia transform into active phagocytes. These cells migrate to the damaged area and adopt an amoeboid morphology, releasing both pro- and anti-inflammatory molecules. They also have the capacity to remove apoptotic cells and debris. As mentioned above, for phagocytosis to occur the expression of specific receptors on the microglial surface is necessary. The principal receptors are the TLRs, which have high affinity for pathogens, and TREM2, which recognizes apoptotic cellular substances (Hsieh et al., 2009). In addition, other receptors also participate in cell-debris clearance (Fc receptors, complement receptors, scavenger receptors (SR), pyrimidinergic receptors P2Y, G-protein coupled,6 (P2RY6), macrophage antigen complex 2 (MAC-2), mannose receptor, and low-density lipoprotein receptor-related protein (LRP) (Fu et al., 2014).

Although microglia are the main agents responsible for phagocytosis of cell debris in the CNS, the complement system can play a primordial role in removing damaged and apoptotic cells (Fakhoury, 2016). Microglial cells can activate the complement by local secretion of the complement component from both the classical and the alternative pathway and also express C3 and C5 (Luo et al., 2011). The complement also participates in the physiological process, termed synaptic pruning. The synapses and axons have to be labeled by complement components $\mathrm{C} 1 \mathrm{q}$ and $\mathrm{C} 3$ before being phagocytosed, which prompts their selective recognition by microglial cells (Paolicelli et al., 2011; Linnartz et al., 2012; Schafer et al., 2012).

Given the central role of microglial cells in neurodegeneration, the evaluation of activated microglia in vivo is an important approach. Positron emission tomography (PET) is the most widely used in vivo method for detecting microglial activation (Owen and Matthews, 2011; Mirzaei et al., 2016). 
It has been found that activated microglia and astrocytes overexpress mitochondrial translocator protein (TSPO) within or surrounding senile plaques. Thus, it has been proposed that neuroimaging of TSPO using PET is a good marker of neuroinflammation (Cosenza-Nashat et al., 2009; Pasqualetti et al., 2015).

\section{AD AND MICROGLIA}

The primary pathogenic process in $\mathrm{AD}$ is the accumulation of $\mathrm{A} \beta$ protein. This protein aggregates into extracellular amyloid plaques, which are the hallmark of this pathology (Southam et al., 2016). The amyloid hypothesis for AD is based on a linear, quantitative, centered neuron model. This model postulates that the initial deposition of $\mathrm{A} \beta$ triggers mechanisms that progressively lead to Tau pathology, synaptic dysfunction, inflammation, neuronal loss and finally to dementia (De Strooper and Karran, 2016). Recently, evidence has been reported that $A \beta$ protein acts by increasing tau pathology through the formation of tau species capable of producing new aggregates (Bennett et al., 2017).

After acute inflammatory damage, the brain glial cells respond to repair the tissue. If the stimulus persists, it produces an inflammatory chronic state that leads to neuronal dysfunction, injury, and loss (Streit et al., 2004; Calsolaro and Edison, 2016). As mentioned before, inflammation is one of the possible causes in the development of $\mathrm{AD}$ (Wyss-Coray, 2006). The increase in $A \beta$ deposition induces the activation of astrocytes as well as microglia (Cagnin et al., 2001). These activated cells can release both pro- and anti-inflammatory mediators, leading to a state of chronic inflammation in the tissue. This inflammation not only occurs in response to $A \beta$ deposition, but is also capable of generating, via feedback mechanisms, more $A \beta$ while weakening the mechanisms responsible for its elimination (Parpura et al., 2012).

The Soluble $A \beta$ oligomers and $A \beta$ fibrils can react to various receptors expressed by microglia, including CD14, CD36, CD47, $\alpha 6 \beta 1$ integrin, class A scavenger receptor, receptor for advanced glycosylation end products (RAGE) and TLRs (Stewart et al., 2010). The RAGE is an important cellsurface receptor for $A \beta$ in the endothelial cells, neurons, and microglia, and increased expression in these cell types has been demonstrated in AD (Yan et al., 1996). The interaction of A $\beta$ with RAGE causes oxidative stress in neurons, enhances inflammatory responses in microglia, and is involved in reversed transport of $\mathrm{A} \beta$ across the $\mathrm{BBB}$ in endothelial cells (Deane et al., 2012). The binding of A $\beta$ to CD36 (cell surface microglial co-receptor) promotes the TLR4 and/or TLR6 phosphorylation and activation, resulting in the production of inflammatory cytokines and chemokines (Stewart et al., 2010).

Recently, an alternative pathway has been described for intracellular signaling produced by the binding of $A \beta$ to microglial cells, activating NLRP3 inflammasome (Heneka et al., 2013; Sheedy et al., 2013). NLRP3 inflammasome is an intracellular protein complex. Their assembly and activation regulates activation of caspase-1, which catalyzes the cleavage and activation of proinflammatory cytokines of the IL-1 $\beta$ family, promoting the secretion of these, now biologically active, cytokines. These cytokines could induce neuronal degeneration (Gold and El Khoury, 2015). In addition, NLRP3 inflammasome activation reduces phagocytosis of $\mathrm{A} \beta$ by microglial cells, thus increasing the $A \beta$ depositions and contributing to the pathogenesis of AD (Garlanda et al., 2013; Gold and El Khoury, 2015).

Microglial cells are important for the normal functioning of neurons in the CNS. They provide trophic support to neurons and regulate synapses. The altered microglial behavior could induce neuronal degeneration in $\mathrm{AD}$ (Southam et al., 2016). During development, microglia are involved in synapse elimination and these mechanisms may be aberrantly reactivated in the aged brain, contributing to the synapse loss in $\mathrm{AD}$. The synapse loss in the hippocampus and association cortices is an early hallmark of $\mathrm{AD}$ and strongly correlates with cognitive impairment (Hong et al., 2016). In the healthy development of the brain, the proteins of complement participate in synapse pruning. Synapses to be cleared express C3 and binding to CR3 on microglia, resulting in microglial phagocytosis of the synapse (Schafer et al., 2012; Southam et al., 2016). In the healthy adult brain, these complement components are downregulated. However, in aging brains, C1q and C3 are highly upregulated and are deposited on synapses, particularly in the hippocampus, the most vulnerable region in the synapse loss in $\mathrm{AD}$ (Bialas and Stevens, 2013). These findings highlight the importance of complement regulation for normal synaptic maintenance (Southam et al., 2016). In addition, it has been shown that $A \beta$ can bind and regulate the expression and localization of complement proteins in the $\mathrm{AD}$ brain. An upregulation has been observed in the complement proteins $(\mathrm{C} 1 \mathrm{q}, \mathrm{C} 3$, and $\mathrm{C} 4)$ localized in senile plaques also known as neuritic plaques (Hong et al., 2016).

Microglial cells can use additional mechanisms for synapsis regulation. The release of brain-derived neurotrophic factor (BDNF) by microglial cells induces synaptic pruning. However, the depletion of this factor in the microglia results in learning and memory impairment (Parkhurst et al., 2013). The activation of the fractalkine receptor (CX3CR1) in microglial cells, increases synaptic strength. However, deficiency in this receptor results in a reduced hippocampal synaptic plasticity (Rogers et al., 2011; Clark et al., 2015).

It has been reported that in the later stages of $\mathrm{AD}$, there is destruction of axons, dendrites, and synapses, in which microglia has a relevant role (Parpura et al., 2012). In AD brains reactive microglia has been found colocalized with amyloid plaques. In addition, the reactive astrocytes accumulate around senile plaques next to the activated microglia (Heneka et al., 2015). In brain, astrocytes as well as microglia are capable of capturing $A \beta$ for degradation (Pihlaja et al., 2011). In AD patients, astrocytes in the entorhinal cortex accumulate $A \beta$, this accumulation being positively correlated with the extent of AD (Nagele et al., 2003). Moreover, astrocytes can also induce microglia to perform $\mathrm{A} \beta$ 
phagocytosis by regulating the release of the apo $\mathrm{E}$ and the ATP-binding cassette (ABCA) protein. Studies in vitro have demonstrated that microglial phagocytosis of $A \beta$ is more effective in the presence of supernatants derived from astrocytes (Terwel et al., 2011). In AD, mutations in ABCA7 can cause a loss of receptor activity, resulting in reduced microglia phagocytic function (Southam et al., 2016).

Microglial senescence can enhance the sensitivity of microglia to inflammatory stimuli; this phenomenon is called "priming" (Heneka et al., 2015). In addition, aged microglia show reduced phagocytic capacity. This process could be due partly to a reduction in the ability of microglia to recognize phagocytic targets (Udeochu et al., 2016). Both inflammation and reduced microglial phagocytic capacity in $\mathrm{AD}$ can contribute to the decline in synaptic plasticity observed in this pathology (Ritzel et al., 2015; Udeochu et al., 2016).

In $\mathrm{AD}$, protein aggregation is caused by declining of protein homeostasis (proteostasis) (Mosher and Wyss-Coray, 2014). As mentioned above, $\mathrm{A} \beta$ deposits can attract and activate microglia. Presumably, microglial proliferation around plaques could serve as a line of defense to limit the deposition of amyloid. Nonetheless, it seems that microglial cells clustered around $\mathrm{A} \beta$ - deposits have become incapable of removing the amyloid (Calsolaro and Edison, 2016). The sustained exposure to cytokines, chemokines and $A \beta$, could be responsible for the functional impairment of microglial cells located around $A \beta-$ deposits (Heneka et al., 2015). In addition, microglial-specific genetic alterations may be related to this microglial dysfunction. The expression of beclin 1, a protein associated with autophagy pathway, is reduced in the brain of patients with $\mathrm{AD}$, leading to disruption in phagocytosis and retromer-mediated recycling of the phagocytic receptors CD36 and TREM2 in microglia (Mosher and Wyss-Coray, 2014).

Similarly, mutations in TREM2 can trigger the loss of phagocytic capacity in microglial cells. TREM2 inhibits proinflammatory cytokine production, facilitates phagocytosis and promotes cell survival. Thus, TREM2 dysfunction could induce the loss of the homeostasis in the tissue (Painter et al., 2015). Missense mutations in TREM2 lead to a significant risk of developing AD (Jonsson et al., 2013; Meyer-Luehmann and Prinz, 2015).

As mentioned above, in $\mathrm{AD}$ the $\mathrm{A} \beta$ peptide that is aggregated extracellularly in the neuritic plaques produces an inflammatory environment and a chronic activation of microglial and astroglial cells (D’Andrea, 2005). Activated microglia can shed MVs in response to several signals, including cytokines. These MVs contain bioactive molecules (i.e., IL-1 $\beta$, proteases, and MHC-II) which modulate the activity of neuronal and non-neuronal cells (Antonucci et al., 2012). In AD patients, the production of MVs is very high, reflecting microgliosis. These extracellular vesicles can be isolated form cerebrospinal fluid (Guerriero et al., 2016).

In patients with $\mathrm{AD}$, an upregulation of $\mathrm{iNOS}$ has been found. In the course of $\mathrm{AD}$, cytokines stimulate iNOS in microglia and astrocytes, generating high NO levels (Vodovotz et al., 1996). NO can interact with signaling cascades and regulate gene transcription, impair mitochondrial respiration or directly induce neuron death by apoptosis or necrosis (Parpura et al.,
2012). In addition, the $\mathrm{NO}$ can promote the nitration of $\mathrm{A} \beta$, increasing their propensity to aggregate (Kummer et al., 2011; Heneka et al., 2015).

In late-onset Alzheimer's disease (LOAD), accumulating $\mathrm{A} \beta$ and NO harm the cells of the cerebral vessel, causing the onset of cerebral amyloid angiopathy (Nelson et al., 2016). The neurovascular unit, constituted by cerebral blood vessels, perivascular glia and neurons, are associated with distinct inflammatory, functional, and morphological alterations in $\mathrm{AD}$ (Heneka et al., 2015). In LOAD, damaged blood vessels can hinder neurogenesis from neural stem cells in the subventricular zone and hippocampus, preventing the processing and storage of new memories (Licht and Keshet, 2015; Chiarini et al., 2016).

Recently, it has been suggested that the involvement of glial cells in $\mathrm{AD}$ is related with the transient receptor potential melastatin member 2 (TRPM2). This receptor, besides regulating synaptic plasticity and glial cell activation, also modulates oxidative stress and inflammation (Yuruker et al., 2015). TRPM2 channel can be activated by $\mathrm{A} \beta$. The activation of these channels in microglia and astrocytes leads to $\mathrm{Ca}^{2+}$ overload and subsequent inflammation and oxidative stress. All of this causes mitochondrial dysfunction, $\left[\mathrm{Ca}^{2+}\right]_{\mathrm{I}}$ increase, $\mathrm{A} \beta$ accumulation, glutamate-receptor dysfunction, and finally plasticity alterations and dementia (Yuruker et al., 2015; Wang et al., 2016).

\section{PARKINSON AND MICROGLIA}

PD is characterized by $\alpha$-synuclein ( $\alpha$-syn) accumulation, dopaminergic neuron loss and inflammation (Beach et al., 2014; Wang et al., 2015). The pathological hallmark of this disorder is the presence of Lewy bodies. The Braak hypothesis has suggested that PD begins in the olfactory bulb or the gastrointestinal tract. These areas are constantly exposed to the environment, and in them, the Lewy bodies accumulate (Kannarkat et al., 2013). Lewy bodies are constituted mainly by misfolded $\alpha$-syn and other intraneuronal protein aggregates such as tau and ubiquitin proteins (Campello et al., 2013; George and Brundin, 2015). The nitration, phosphorylation, and ubiquitination of $\alpha$-syn can promote their pathological accumulation, inducing neurodegeneration (Giasson et al., 2000; Tofaris et al., 2003; Anderson et al., 2006). In addition, missense mutations in $\alpha$ syn can produce the protein aggregation in familial PD (Conway et al., 1998).

Reportedly, $\alpha$-syn can induce microglial activation, which in turn can promote $\alpha$-syn phagocytosis (Cao et al., 2012) and neuroinflammation. The neuroinflammation leads to the loss of dopaminergic neurons and drives the chronic progression of neurodegeneration in PD (Schapansky et al., 2015). Accumulations of activated microglia have been found around dopaminergic neurons in postmortem human brains (Hamza et al., 2010). Microglial cells can be activated by $\alpha$-syn, via TLRs, initiating an immune response (Fellner et al., 2013). Specifically, the stimulation of TRL2 and TRL4 in the microglia induces signaling cascades involved in the inflammatory response. It has been shown in PD patients that TLR2 colocalized with CD68+ amoeboid microglia indicates 
microglial activation at the sites of neuronal loss (Doorn et al., 2014). Also, TRL4 can induce microglial phagocytosis of $\alpha$-syn. Deficiencies in this receptor can prompt poor $\alpha$-syn clearance and neurodegeneration (Fellner et al., 2013).

The clearance of $\alpha$-syn also can be promoted by the leucinerich repeat kinase 2 (LRRK2) gene. This gene has been proposed as a regulator of the microglial response (Schapansky et al., 2015). LRRK2 is the most commonly mutated gene in both idiopathic and familial PD. Pathogenic mutations in LRRK2 influence the ability of microglia to internalize and degrade $\alpha$-syn, exacerbating $\alpha$-syn-induced microglial pathology, and neuroinflammation (Schapansky et al., 2015). In addition, other genes whose mutations are responsible for rare familial forms of PD have been identified, including, SNCA, PARKIN, DJ-1, and PINK1 (Chao et al., 2014).

Persistent microglial activation is known to exert harmful effects that result in dopaminergic neuron death. One of the most important signaling pathways associated with the microglial activation in PD involves nuclear factor-kappa B (NF$\mathrm{kB}$ ) (Zhang et al., 2017). The activation of this factor could increase the release of proinflammatory cytokines such TNF$\alpha$ and interleukin $1 \beta$ by microglial cells (Mogi et al., 1996; McLaughlin et al., 2006). In addition, proinflammatory mediators such as TNF- $\alpha$, IL- $1 \beta$, and IFN- $\gamma$ have been found at higher levels in the midbrain of PD patients (Wang et al., 2015). Immunomodulators, including the CX3CL1, CD200, CD22, CD47, CD95, and neural cell adhesion molecule, sustain the rest state of microglia under normal conditions (Chang et al., 2000; Sheridan and Murphy, 2013). In rat PD models, both deficiency CX3CL1 or CX3CR1 as well as the dysfunction of CD200CD200R signaling have been shown to increase microglial activation and the degeneration of DA neurons (Wang et al., 2011; Zhang et al., 2011).

The cytokines released by activated microglia can attract peripheral immune cells (e.g., CD4 T-cell) to the brain. In vivo and in vitro studies have demonstrated that overexpression of $\alpha$ syn can induce the MHC-II expression by microglia. The MHC-II expression in microglia cells can play an important role in the immune responses (innate and adaptive) in PD (Michelucci et al., 2009; Harms et al., 2013; Gonzalez et al., 2015).

In addition, dopaminergic neurons seem to be especially sensitive to several factors that can induce cell damage and eventually cell death. It has been suggested that mitochondrial malfunction leads to reduced energy metabolism and induces neuroinflammation via $\mathrm{NO}$ and ROS production, which ultimately entails neurodegeneration (Vivekanantham et al., 2015). The production of $\mathrm{NO}$ and superoxide exerted by activated microglia in PD can cause the degeneration of dopaminergic neurons (Appel et al., 2010). The high cytosolic concentrations of free DA can produce oxidative stress and can interact with $\alpha$-syn, promoting the neurodegenerative process (Mosharov et al., 2006). In addition, the neuromelanin (dark, complex endogenous polymer derived from DA) can activate microglial cells, inducing neuroinflammation and neurodegeneration of dopaminergic neurons in PD (Zecca et al., 2008; Herrera et al., 2015).
Neuroinflammation is produced by the set of integrated responses of all the CNS immune cells including microglia, astrocytes and infiltrating T-lymphocytes (Le et al., 2016). Gliosis in the PD is an atypical activation where astrogliosis is largely absent while the microglia is highly activated by the disease. The low astroglial response may be caused by degeneration due to an increase of $\alpha$-syn in the astrocyte (Stefanova et al., 2001; Orr et al., 2002; Sofroniew and Vinters, 2010). Astrocytes are responsible for secreting glutathione and transporting to neurons in response to neural excitatory stimuli. A lower level of glutathione has been detected in the CNS of PD patients, and thus the antioxidant capacity in the tissue could be impaired, probably secondary to the astroglial defect (Olanow and Tatton, 1999).

Recently, the kinurenic pathway (KP) has been implicated in the inflammatory and neurotoxic processes in PD. Astrocytes produce a neuroactive component of KP, kynurenic acid, considered to be neuroprotective. By contrast, quinolinic acid, released by microglia, can activate the NMDA receptorsignaling pathway, leading to excitotoxicity and increasing the inflammatory response. Based on this, KP may represent an important target to prevent the progression of the underlying neurodegeneration observed in PD (Lim C. K. et al., 2017).

Nowdays, it has been reported that prothrombin kringle2 (pKr-2), which is a domain of prothrombin (which is produced by active thrombin), could be involved in PD. Also, pKr-2 induced DA neuronal death in an experimental PD model (Kim et al., 2010). In addition, in PD patient's pKr-2 expression is significantly increased and co-localized in activated microglial in the substantia nigra, leading to disruption of the nigrostriatal DA projection. This disruption could be mediated through the neurotoxic inflammatory events brought about by the pKr-2 upregulation, wich trigger microglial activation via TLR4. On the basic of these results, limiting $\mathrm{pKr}$-2-induced microglial activation may be an effective therapeutic strategy for protecting DA neurons (Leem et al., 2016).

\section{NEURODEGENERATIVE DISEASES AND THE EYE}

\section{Alzheimer's Disease}

Classically, the damage in $\mathrm{AD}$ was thought to be restricted mainly to the brain. However, in the last few decades it has been demonstrated that patients with $\mathrm{AD}$ often develop visual anomalies, which are correlated with abnormalities in the eye. Among them, there is a reduction in the number of optic nerve head axons and a decrease in the thickness of the peripapillary and macular retinal nerve fiber layer (RNFL) (Tsai et al., 1991; Hedges et al., 1996; Danesh-Meyer et al., 2006; Iseri et al., 2006; Paquet et al., 2007; Garcia-Martin et al., 2014; SalobrarGarcia et al., 2015; Salobrar-García et al., 2016c) (Table 1). One of the earliest symptoms of $\mathrm{AD}$ could be the thinning of the RGC layer and visual spatial impairment (Kesler et al., 2011). Postmortem studies in AD retinas, have demonstrated that, in addition to RGC loss, melanopsin retinal ganglion cells (mRGC) are lost. There is evidence that mRGCs may be affected primarily 
by $\mathrm{A} \beta$ pathology in $\mathrm{AD}$ (La Morgia et al., 2011). This mRGC deficiency could be correlated with a circadian dysfunction (La Morgia et al., 2011) in which AD patients tend to be more active during the night in comparison with the day (Hatfield et al., 2004; Hooghiemstra et al., 2015). In addition, in the retina of $\mathrm{AD}$ patients as well as $\mathrm{AD}$ human postmortem specimens the presence of $A \beta$ plaques has been demonstrated. $A \beta$ deposition was observed from the outer nuclear layer (ONL) to nerve fiber layer (NFL), being more abundant in the superior region of the retina where greater neuronal degeneration has been detected (Hardy and Selkoe, 2002; Selkoe, 2004, 2008; Alexandrov et al., 2011; Ratnayaka et al., 2015; Hart et al., 2016; Table 1). In AD patients, the alloform $A \beta 42$ is increased (Alexandrov et al., 2011). This alloform presents higher cellular toxicity, more aggregation capacity, and a more direct relation with AD pathology (Qiu et al., 2015). A $\beta 42$ peptide accumulation in the retina may contribute to retinal degeneration and visual impairment in AD (Hardy and Selkoe, 2002; Selkoe, 2004, 2008; Alexandrov et al., 2011; Ratnayaka et al., 2015; Hart et al., 2016; Figure 1A, Table 1). However, recently Williams et al. in $\mathrm{AD}$ patients found no evidence of deposits or accumulations of Tau, A $\beta$, TDP-43, ubiquitin or $\alpha$-syn in any part of the eyeball (Williams E. A. et al., 2017).

$\mathrm{A} \beta$ plaques have also been detected in the retina of transgenic mouse models of $\mathrm{AD}\left(\mathrm{APP}_{\text {swe }} / \mathrm{PS}_{\triangle \mathrm{E} 9}, \mathrm{Tg} 2576 \mathrm{AD}, 3 \times \mathrm{xg}-\mathrm{AD}\right.$, PSAPP, 5xFAD; Hsiao et al., 1996; Holcomb et al., 1998; Takeuchi et al., 2000; Lukiw et al., 2001; Oddo et al., 2003; Kumar-Singh et al., 2005; Oakley et al., 2006; Philipson et al., 2010; KoronyoHamaoui et al., 2011). Overall, in these mice, $A \beta$ plaques were found principally in the NFL, ganglion cell layer (GCL), inner plexiform layer (IPL), inner nuclear layer (INL) and outer plexiform layer (OPL) (Table 1). In $\mathrm{APP}_{\text {swe }} / \mathrm{PS}_{\triangle \mathrm{E} 9}$ transgenic mice, $A \beta$ plaques appeared in the retina of young transgenic $\mathrm{AD}$ mice at presymptomatic stages, as early as 2.5 months, preceding their detection in the brain. This situation points out a correlation between retinal and brain pathology in AD. The detection of retinal $A \beta$ might potentially provide an alternative noninvasive approach to assess the progression of $\mathrm{AD}$. In relation to this last point, it has been demonstrated that the systemic administration of curcumin to $\mathrm{AD}$ mice resulted in specific in vivo labeling of retinal $A \beta$ plaques. This finding provides the basis for the development of a high-resolution noninvasive optical-imaging technique for detecting $\mathrm{A} \beta$ plaques in the retina, allowing the early diagnosis and follow up of $\mathrm{AD}$ (KoronyoHamaoui et al., 2011; Kayabasi et al., 2014). In addition, curcumin has been revealed to be a novel agent for treating $\mathrm{AD}$ through different neuroprotective mechanisms, such as inhibition of $A \beta$ aggregation and decrease in neuroinflammation (Maiti and Dunbar, 2016; Lakey-Beitia et al., 2017).

In addition to $A \beta$ plaques, $p$ Tau was observed from OPL to GCL in the retina of AD patients. Also, pTau has been found from the ONL to GCL in the transgenic mouse (Liu et al., 2009). It has been postulated that pTau could be potentially a marker for the $\mathrm{AD}$ disease (Lim J. K. et al., 2016). In a model of transgenic mice P301S tau, early accumulation of pTau and BIII-tubulin in the NFL of the retina was demonstrated. This accumulation was accompanied by somatodendritic redistribution of pTau and the subsequent development of tau inclusions in a group of RGCs. In the optic nerve of this transgenic model, at 5 months of age, damaged axons were detected presenting phospho-tau, neurofilaments, amyloid precursor protein and ubiquitin accumulations, as well as disordered filaments and degenerating mitochondria and organelles (Gasparini et al., 2011). These observations suggest that tau may alter axonal transport. This alteration is an early event in tau-induced neuronal dysfunction and corroborates previous findings in mouse models of tautopathy and glaucoma, showing that axonal degeneration precedes neuronal loss (Schlamp et al., 2006; Leroy et al., 2007; Figure 1A, Table 1).

A significant upregulation of inflammation (evidenced by astroglial and microglial activation) has been found in the retinas of $\mathrm{AD}$ mouse models in relation to $\mathrm{A} \beta$ plaques (Parnell et al., 2012). Ning et al. (2008) observed an age-dependent increment in $\mathrm{A} \beta$ in the retina of the double transgenic mice model $\mathrm{APP}_{\text {swe }}$ / $\mathrm{PS}_{\triangle \mathrm{E} 9}$. This increment was accompanied by increases in the inflammatory cytokine MCP-1, the microglial marker F4/80, and the TUNNEL-positive cells in the RGC layer. Thus, the authors suggested that $A \beta$ played a major role in the inflammation and neurodegeneration in $\mathrm{AD}$. In the same transgenic model, Perez et al. (2009) observed significantly greater microglial activity. Microglial activation could occur early in the retina and could be involved in the elimination or turnover of $A \beta$ deposition. In addition, activated microglia could trigger a neuroinflammatory response, which may contribute to a disorganization of the retina, as demonstrated by electroretinogram functional alterations (Krasodomska et al., 2010; Table 1). This neuroinflammatory response associated with $A \beta$ plaques and pTau, has also been observed in Tg2576AD mice. In these animals, there was a significant increase in Ibal cells (a microglial marker) and an increase in the glial fibrillary acidic protein (GFAP) immunoreactivity (a marker of astrocytes) (Figure 1A). The vaccination with $A \beta$ oligomer antigen reduced $A \beta$ retinal deposits in these transgenic mice. However, the microvascular $A \beta$ deposition as well as the microglial infiltration and astrogliosis were increased and were associated with the disruption of retinal architecture (Liu et al., 2009). Other studies support the involvement of the neuroinflammation in the $\mathrm{AD}$ progression. These studies analyzed the role of the complement in this disease (Parnell et al., 2012). Deficits have been found in the expression of the innate immune-repressor complement factor $\mathrm{H}$ $(\mathrm{CFH})$ associated with significant increases of $\mathrm{A} \beta 42$ peptides in brains and retinas of transgenic models of AD (Veerhuis, 2011). $\mathrm{CFH}$ functions as a cofactor in the inactivation of $\mathrm{C} 3 \mathrm{~b}$ in the alternative complement pathway, and thus low CFH levels result in complement activation, triggering inflammation in the retina and brain (Alexandrov et al., 2011). In the transgenic rat model (TgF344-AD) also has been observed, along with $\mathrm{A} \beta$ deposition, microglial recruitment, and complement activation in association with a decline in visual function (Tsai et al., 2014; Table 1).

\section{Parkinson's Disease}

As mentioned above, PD is a motor disorder associated with degeneration of dopaminergic neurons in the substantia nigra (Inzelberg et al., 2004). In this disease, high levels of $\alpha$-syn 
TABLE 1 | Retinal changes associated with AD, PD, and glaucoma.

\begin{tabular}{|c|c|c|c|c|}
\hline & & $A D$ & PD & Glaucoma \\
\hline \multicolumn{2}{|c|}{ Inner retinal involvement } & La Morgia et al., 2011 & $\begin{array}{l}\text { Bodis-Wollner, 1990; Tatton et al., } \\
\text { 1990; Surguchov et al., 2001; } \\
\text { Cuenca et al., 2005; Hajee et al., } \\
\text { 2009; Bodis-Wollner et al., } 2014\end{array}$ & Rojas et al., 2014 \\
\hline $\begin{array}{l}\text { Protein deposits in } \\
\text { retina }\end{array}$ & $A \beta$ & $\begin{array}{l}\text { Hsiao et al., 1996; Holcomb } \\
\text { et al., 1998; Takeuchi et al., } \\
\text { 2000; Lukiw et al., 2001; Hardy } \\
\text { and Selkoe, 2002; Oddo et al., } \\
\text { 2003; Selkoe, 2004, 2008; } \\
\text { Kumar-Singh et al., 2005; Oakley } \\
\text { et al., 2006; Philipson et al., } \\
\text { 2010; Alexandrov et al., 2011; } \\
\text { Koronyo-Hamaoui et al., 2011; } \\
\text { Kayabasi et al., 2014; Qiu et al., } \\
\text { 2015; Ratnayaka et al., 2015; } \\
\text { Hart et al., } 2016\end{array}$ & & $\begin{array}{l}\text { McKinnon et al., 2002; McKinnon, 2003; Goldblum } \\
\text { et al., } 2007\end{array}$ \\
\hline \multicolumn{2}{|l|}{ Microglial activation } & $\begin{array}{l}\text { Ning et al., 2008; Perez et al., } \\
\text { 2009; Parnell et al., } 2012\end{array}$ & $\begin{array}{l}\text { Chen et al., 2003; Nagel et al., 2009; } \\
\text { Cho et al., } 2012\end{array}$ & $\begin{array}{l}\text { Kreutzberg, 1995; Neufeld et al., 1997; Giulian and } \\
\text { Ingeman, 1988; Wax et al., 1998; Neufeld, 1999; } \\
\text { Shareef et al., 1999; Tezel et al., 2001; Yang et al., } \\
\text { 2001b; Yuan and Neufeld, 2001; Naskar et al., } \\
\text { 2002; Steele et al., 2005; Taylor et al., 2005; } \\
\text { Nakazawa et al., 2006; Stasi et al., 2006; Vidal } \\
\text { et al., 2006; Farina et al., 2007; Inman and Horner, } \\
\text { 2007; Johnson et al., 2007; Hammam et al., 2008; } \\
\text { Tezel, 2009; Ebneter et al., 2010; Graeber and } \\
\text { Streit, 2010; Luo et al., 2010; Bosco et al., 2011, } \\
\text { 2012; Kettenmann et al., 2011; London et al., 2011; } \\
\text { Bosco et al., 2012; Gallego et al., 2012; Varnum } \\
\text { and Ikezu, 2012; de Hoz et al., 2013; Gramlich } \\
\text { et al., 2013; Pinazo-Duran et al., 2013; Astafurov } \\
\text { et al., 2014; Cherry et al., 2014; Gonzalez et al., } \\
\text { 2014; Jones and Bouvier, 2014; Lee et al., 2014; } \\
\text { Rojas et al., 2014; Karlstetter et al., 2015; Madeira } \\
\text { et al., 2015; Ransohoff and El Khoury, 2015; } \\
\text { Chidlow et al., 2016; Bolos et al., 2017; Williams E. } \\
\text { A. et al., 2017 }\end{array}$ \\
\hline
\end{tabular}


TABLE 1 | Continued

\begin{tabular}{|c|c|c|c|}
\hline & $A D$ & PD & Glaucoma \\
\hline Blood-retinal barrier breakdown & & & $\begin{array}{l}\text { Farina et al., 2007; Tezel, 2009; London et al., 2011; } \\
\text { Howell et al., 2012; Gonzalez et al., 2014; } \\
\text { Karlstetter et al., 2015; Breen et al., } 2016\end{array}$ \\
\hline
\end{tabular}

Visual impairment
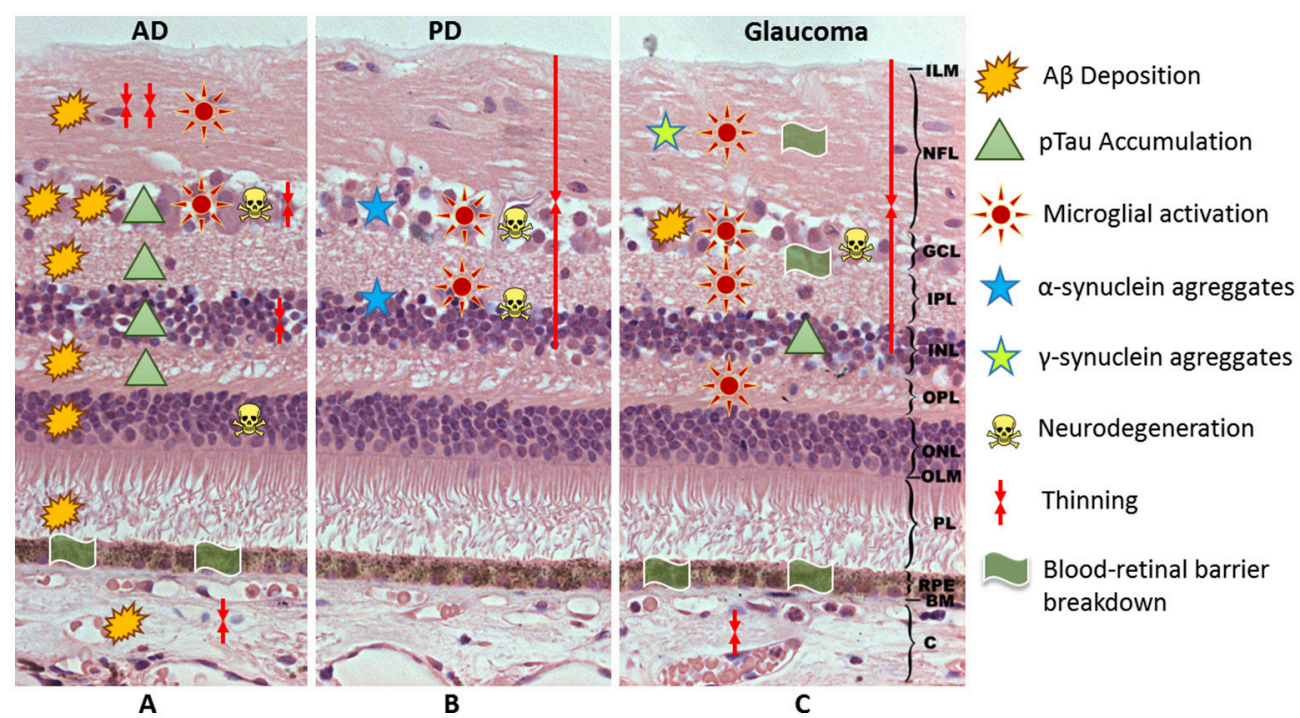

FIGURE 1 | Schematic representation of the hypothetical events associated with the neuroinflammation in AD (A), PD (B), and glaucoma (C). AD, Alzheimer's Disease; PD, Parkinson's Disease; ILM, inner limitant membrane; NFL, nerve fiber layer; GCL, ganglion cell layer; IPL, inner plexiform layer; INL, inner nuclear layer; OPL, outer plexiform layer; ONL, outer nuclear layer; OLM, outer limitant membrane; PL, photoreceptor layer; RPE, retinal pigment epithelium; BM, Bruch membrane; $\mathrm{C}$, choroid; $A \beta$, beta-amyloid; pTau, phosphorylated tau.

are found in midbrain dopaminergic neurons (Neystat et al., 1999; Solano et al., 2000; Braak et al., 2003; Kingsbury et al., 2004; Alafuzoff and Parkkinen, 2014). Moreover, abnormalities in visual function have been reported (Bodis-Wollner, 1990; Nowacka et al., 2014) in PD patients and correlated with changes in retinal tissue (La Morgia et al., 2013; Yu et al., 2014) (Table 1).

In the normal retina of vertebrates, $\alpha$-syn is expressed at photoreceptor axon terminals of vertebrates, as well as in several subtypes of bipolar and amacrine retinal cells. This protein is present in presynaptic, but not postsynaptic, terminals of retinal neurons in both IPL and OPL, where it could be associated with synaptic vesicles to modulate neurotransmission
(Martinez-Navarrete et al., 2007). However, $\alpha$-syn aggregates are related to neurodegenerative disorders, including PD. In postmortem PD eyes, $\alpha$-syn aggregates have been observed inside the neurons of different retinal layers, including the border of the INL, the IPL, and the GCL. These locations suggest a substrate for the visual impairment in PD (BodisWollner et al., 2014). Maurage et al. also reported the presence of $\alpha$-syn inclusions in the OPL and a lower cone density in a patient suffering dementia with Lewy bodies (Maurage et al., 2003). Additionally, in transgenic mice overexpressing $\alpha$-syn, an accumulation of this protein has been found in the INL, GCL, and NFL (Surguchov et al., 2001; Figure 1B, Table 1). 
In $\mathrm{PD}$, in addition to substantia nigra dopaminergic neuron degeneration, the DA content in the retina diminishes. This deficiency could alter visual processing by altering the ganglion cells receptive fields (Djamgoz et al., 1997). Retinas having a dopaminergic deficiency associated with the loss of amacrine cells, which provide input to the ganglion cells, can lose RGCs. This fact is has been observed both in human PD and in PD model in monkeys treated with 1-methyl-4-phenyl-1,2,3,6tetrahydropyridine (MPTP) (selective neurotoxin which destroys DA neurons) (Bodis-Wollner, 1990; Tatton et al., 1990; Cuenca et al., 2005). This loss can be mediated by the impoverished dopaminergic input, which contributes to an alteration in the glutamate production and the atrophy of inferotemporal circumpapillary RNFL in PD patients (Inzelberg et al., 2004). These data agree with the observations in $\mathrm{PD}$ patients, in which a thinning of inner retinal layer (15-20\%) has been demonstrated in the macular region. This percentage of thinning does not necessarily cause a vision loss (Hajee et al., 2009; Figure 1B, Table 1). Also in the retina of mice treated with rotenone (pesticide that elicits DA neuron degenerations), an experimental model of $\mathrm{PD}$, a correlation between functional and structural alterations were located in the retina, specifically in the photoreceptors and their synaptic connections with secondorder neurons (Esteve-Rudd et al., 2011).

Very few studies analyze retinal glial cells in PD. In a transgenic mouse model overexpressing $\alpha$-syn, an accumulation of $\alpha$-syn has been found in glial cells of the INL (Surguchov et al., 2001). In a PD model with the administration of MPTP increased GFAP immunostaining, glutamine synthetase (Müller cell marker), and CD11b (microglial marker) were detected, indicating an activation of retinal glial cells (Chen et al., 2003). In the same experimental model, Nagel et al. also observed astrogliosis in retinal tissue, without changes in the number of tyrosine hydroxylase $(\mathrm{TH})+$ amacrine cells, postulating that other retinal neurons can be affected, even non-neuronal cells (Nagel et al., 2009). In addition, a non-proliferative gliosis of GFAP+ Müller cells was found in the MPTP model of PD. This gliosis was accompanied of milder declines in $\mathrm{TH}+$ amacrine cells, followed by stronger recoveries without neurogenesis (Cho et al., 2012). Müller cells constitute the main glial cell type in the retina where it interacts with virtually all cells displaying functions relevant to retinal physiology. Müller cells are able to synthesize and release DA to the extracellular medium. Thus, the dopaminergic Müller cells can be used as a source of DA in cell-therapy procedures (Stutz et al., 2014; Table 1).

\section{Glaucoma}

Glaucoma, the second leading cause of blindness in the world, is characterized by the irreversible RGC loss, leading to a vision loss (Quigley and Broman, 2006). In the early stages of the disease, the reactivation of the glial cells leads to the progression of glaucomatous damage (Tezel, 2009). As mentioned above, when neurons are damaged, microglial cells respond by adopting an activated phenotype (Kreutzberg, 1995; Graeber and Streit, 2010). In glaucoma, activated microglia can exhibit morphological changes, proliferate, migrate, or can change the expression of different enzymes, receptors, growth factors, and cytokines (Rojas et al., 2014). An overexpression of these latter inflammatory mediators can contribute to retinal degeneration (Langmann, 2007; Karlstetter et al., 2010). Also, microglia can act as antigen-presenting cells and even transform into phagocytes (Luo et al., 2010; Kettenmann et al., 2011; Karlstetter et al., 2015; Ransohoff and El Khoury, 2015). Unfortunately the role of the microglia in the pathophysiology of glaucoma is poorly understood, and thus better knowledge of the function of microglial cells in this disease is necessary.

As mentioned above, microglial activation is one of the first events in glaucomatous neurodegeneration (Williams P. A. et al., 2017), but even this activation is prior to the RGC loss (Ebneter et al., 2010; Bosco et al., 2011). In experimental glaucoma models, it has been observed that after treatment with minocycline (Bosco et al., 2008) or with a high dose of irradiation (Bosco et al., 2012), there was a reduction of microglial activation and thus lower RGC death. In addition, in DBA-2J mice a significant quantitative correlation has been established between the microgliosis and the axon loss in the optic nerve (Bosco et al., 2016; Figure 1C, Table 1).

Neurons can induce an inflammatory response in microglial cells after an injury. Nucleotides released by damaged neurons can up-regulate the purinergic receptors of the microglia, activating their phagocytic ability, motility, and migration (Koizumi et al., 2007; Ohsawa et al., 2007; Wu et al., 2007). It has been demonstrated, in an experimental mouse glaucoma model, that deficiencies in the activation of CX3R1 increase microglial activity, neurotoxicity, and the RGC death (Wang et al., 2014). In addition, in the experimental model of glaucoma, there is an early change in the CD200R/CD200 expression which regulates the microglial activity and precedes RGC death (Taylor et al., 2011). The damaged neurons can release head-shock proteins (HSP), triggering the oxidative response in the microglial cells. These proteins can activate the innate immune system via TRLs in the glaucoma (Tezel, 2009; Karlstetter et al., 2015). In the human glaucoma, high levels of HSP27, HSP60, HSP7, and antibodies against HSPs (Cagnin et al., 2001; Streit et al., 2004; Wyss-Coray, 2006; Stewart et al., 2010; Parpura et al., 2012; Calsolaro and Edison, 2016; De Strooper and Karran, 2016; Bennett et al., 2017) have been found. Furthermore, the dying neurons release the protein $\mathrm{HMGB} 1$, which binds to the CD11b receptor of the microglia to induce the production of inflammatory and neurotoxic factors. In experimental glaucoma the elimination of the $\mathrm{CD} 11 \mathrm{~b}$ receptor has a neuroprotective role since it prevents the microglial activation (Nakazawa et al., 2006).

In glaucoma patients, an overexpression of $\gamma$-synuclein has been demonstrated in ganglion cell axons as well as in glial cells of the lamina and postlamina cribosa of the optic nerve. Synuclein has an important role in neurodegenerative diseases, and these findings suggest possible synuclein involvement in glaucomatous alterations in the optic nerve (Surgucheva et al., 2002).

In experimental glaucoma and in the $\mathrm{DBA} / 2 \mathrm{j}$ spontaneous mouse glaucoma model, amyloid precursor protein and $A \beta$ were found in the RGCs (Figure 1C) in relation to increased IOP (McKinnon et al., 2002; McKinnon, 2003; Goldblum et al., 2007). In addition, abnormal tau (AT8) and phosphorylated tau were found to be present in human ocular tissues of uncontolled IOP 
and in donor eyes with glaucoma (Gupta et al., 2008; Ning et al., 2008). This implies that $A \beta$ accumulation in the retina is involved in the pathogenesis of glaucoma, this $\mathrm{A} \beta$ deposition being related to microglial activation and neuroinflammation (Bolos et al., 2017; Figure 1C, Table 1).

When microglia are activated, they can adopt different morphologies. In experimental models of glaucoma, activated microglia acquire several morphological phenotypes: stellate cells with thick processes, hyper-ramified cells, rounded cells, amoeboid cells (which act as macrophages, phagocytizing cellular debris) and rod-like microglia. The rod-like microglia are related to neurodegeneration, in the experimental glaucoma model, and the presence of this cell type is restricted to eyes with neuronal damage. It seems that the rod-like microglia might be involved in the active removal or "stripping" of the synaptic contacts (Gallego et al., 2012; de Hoz et al., 2013; Rojas et al., 2014).

In addition to the different morphologies, activated microglia can adopt different functional phenotypes in response to neuronal damage. After injury, the cytokines released by the damaged cells (e.g., IFN- $\gamma$ ) give rise to the microglial activation, acquiring a M1-like phenotype. This phenotype is characterized by production of proteolytic enzymes and pro-inflammatory cytokines (TNF- $\alpha$, IL-1 $\beta$, IL-6, IL-12, and NO) promoting tissue inflammation (Varnum and Ikezu, 2012; Gonzalez et al., 2014; Jones and Bouvier, 2014). In human glaucoma and in the experimental models of glaucoma, high levels of these proinflammatory cytokines have been found (Neufeld et al., 1997; Shareef et al., 1999; Tezel et al., 2001; Nakazawa et al., 2006; Vidal et al., 2006; Lee et al., 2014; Madeira et al., 2015).

In experimental glaucoma, it has been observed that the activated microglia can migrate to remove the damaged or dead cells (Bosco et al., 2012; Rojas et al., 2014). In the human glaucoma the amoeboid microglia are located in the lamina cribrosa phagocyting the damaged axons (Neufeld, 1999). The morphology change of the microglia from the ramified shape to the amoeboid phagocytic shape is associated with the expression of different surface markers such as: MHC-II (OX6), CD68, Griffonia simplicifolia isolectin B4, complement receptor 3 (CD11b/CD18, OX42), and F4/80 (Kreutzberg, 1996; Streit et al., 1999). In a unilateral experimental glaucoma model, CD68 expression (a member of the scavenger-receptor family) was observed in the retinal microglia (Rojas et al., 2014). The migration and the proliferation of the microglial cells are regulated by soluble factors or by the extracellular matrix changes of damaged CNS tissues. It has been found that microglia of the optic-nerve head express different matrix metalloproteinases and their inhibitors, indicating their participation in the remodeling of the extracellular matrix (Yuan and Neufeld, 2001; Garden and Möller, 2006).

The activation of the microglia also involves higher numbers of microglial cells. This fact it has been observed in human glaucoma and in glaucoma animal models (Giulian and Ingeman, 1988; Yuan and Neufeld, 2001; Naskar et al., 2002; Inman and Horner, 2007; Johnson et al., 2007; Gallego et al., 2012; de Hoz et al., 2013; Rojas et al., 2014). The microglia mitosis can be stimulated by neurotrophic factors (BDNF, NT-3) and several cytokines (macrophage colony-stimulating factors, granulocyte macrophage CSF, IL-1 $\beta$, IL-4, and IFN- $\gamma$ ) (Garden and Möller, 2006).

In the classical M1 activation, the MHC II, CD86, and Fc $\gamma$ receptors are up-regulated, because this phenotype is oriented to antigen presentation and the killing of intracellular pathogens (Taylor et al., 2005; Cherry et al., 2014). Under physiological conditions, some microglial cells express very low levels of MHCII, although certain pro-inflammatory cytokines (e.g., TNF- $\alpha$ or IFN- $\gamma$ ) can upregulate MHC-II expression by microglial cells. In this context, both for glaucoma patients (Yang et al., 2001b; Tezel, 2009; Ebneter et al., 2010) and in animal models of glaucoma (Ebneter et al., 2010; Gallego et al., 2012; de Hoz et al., 2013; Rojas et al., 2014) there is evidence for increased expression of MHC-II molecules in glial cells. In a glaucoma model, after 15 days of ocular hypertension (OHT), most of microglial cells were MHC-II + while the CD86 expression was observed only in some amoeboid and rounded Iba-1+cells in the NFL and the GCL (Rojas et al., 2014). The fact that most of microglial cells were CD86- could prevent T-cell activation by their omission of co-stimulation, leading to a downregulation of the immune response (Broderick et al., 2000). In addition, in an experimental glaucoma model the MHC-II upregulation by the activated microglia in the optic nerve could be associated with more severe RGC degeneration (Chidlow et al., 2016). It has been observed in an experimental glaucoma model that caffeine administration decreases the microglia MHC-II upregulation reducing microglial activation and increasing RGC survival (Madeira et al., 2016).

After M1 activation, the microglial cells can return to a state of rest, adopting a transitory state of $\mathrm{M} 2$ activation. In this state, the microglia can upregulate CD68, CD206, and Ym1 (Menzies et al., 2010; Komori et al., 2011; Varnum and Ikezu, 2012; Jones and Bouvier, 2014; Zhou et al., 2014). In an experimental model of unilateral glaucoma, it was observed that the only cells expressing Ym1 were amoeboid Iba-1 + cells in the NFL and GCL of the OHT retinas. The authors postulated that most of the microglial cells in this OHT model were serving functions not related with the M2 microglial phenotype (Rojas et al., 2014).

In glaucomatous eyes, the chronic stress in the tissue can induce the rupture of the blood-retinal barrier, allowing the contact of nervous tissue of the retina and the optic nerve with systemic immune cells (Tezel, 2009). In addition, chemokines (CCL2, CCL5, CCL20, CXCL10, CXCL12, CXCL1, CXCL2, and CX3CL1) released by reactive astrocytes can recruit dendritic cells, microglia, monocytes/macrophages, and T-cells into the inflamed tissue (Farina et al., 2007; Gonzalez et al., 2014). In a chronic glaucoma model DBA/2J, the loss of CX3CL1 signaling increased the infiltration of peripheral macrophages (Breen et al., 2016). The role of monocytes in the survival of RGCs is controversial. In an experimental model of OHT it was observed that an increased number of monocytes could be protective (London et al., 2011). However, in a genetic model of glaucoma (DBA/2J) the irradiation that lowered the number of monocytes boosted RGC survival (Howell et al., 2012).

In addition, the blood retinal barrier breakdown (Figure 1C, Table 1) can allow the entry of complement proteins, thus activating the complement in the retinal tissue (Karlstetter et al., 
2015). For retinal homeostasis, the level of complement proteins should be low. However, the complement constituents can be activated by inflammatory cytokines (e.g., TNF- $\alpha$, INF- $\gamma$, and IL6) produced under inflammatory conditions such as glaucoma (Karlstetter et al., 2015). In the retina of the glaucomatous eyes an upregulation of the component complement $\mathrm{C} 1 \mathrm{q}$ has been observed (Steele et al., 2005; Stasi et al., 2006). Microglial cells respond to $\mathrm{C} 1 \mathrm{q}$ upregulation by eliminating the targeted synapses (Steele et al., 2005; Stasi et al., 2006). Thus, the involvement of the immune system in glaucomatous pathology has been postulated. Recently, it has been suggested that oral microbiome could be related to glaucoma pathophysiology, through microglial activation mediated through TLR4 signaling and complement upregulation (Astafurov et al., 2014). Apart from the chronic activation of resident immunoregulatory glial cells, the presence of plasma cells in the retina, and the complement activation (Tezel, 2009), high levels of autoantibodies and deposition of immunoglobulins have been found in the glaucomatous neurodegeneration (Wax et al., 1998; Hammam et al., 2008; Gramlich et al., 2013; Pinazo-Duran et al., 2013). It has even been speculated that the glaucoma would be mediated by an autoimmune mechanism and that both innate and adaptive responses accompany this pathology (Tezel, 2009, 2013). The serum of glaucoma patients has been found to contain high levels of antibodies (e.g., against HSPs; Maruyama et al., 2000; Wax et al., 2001; Tezel et al., 2004; Grus et al., 2008). Moreover, serum alteration of the populations of T-cell repertoires and of interleukin-2 receptors has been detected (Yang et al., 2001a). In view of the evidence mentioned above, the immune response could be involved in the pathogenesis of the glaucoma.

\section{CONCLUSION}

$\mathrm{AD}, \mathrm{PD}$, and glaucoma are neurodegenerative diseases that share a common pathogenic mechanism, in which the neuroinflammation, in the form of microglial activation, plays an important part. The differential activation of microglia (M1 or M2 phenotypes) can produce a neurotoxic or neuroprotective environment, and could constitute a key in neuroinflammation regulation. In the search for a new strategy to control neuroinflammation, it might be more effective to change the M1 phenotype to the M2 phenotype than to block microglial activation completely. In the regulation of microglial activation, several cell types including, neurons, astrocytes, and $\mathrm{T}$-cells are involved. When the neuroinflammatory process is triggered by protein aggregates ( $A ß, \alpha$-syn, pTau etc.), peripheral immune cells infiltrate CNS and prompt more activation on resident microglia, favoring neuroinflammatory processes.

\section{REFERENCES}

Alafuzoff, I., and Parkkinen, L. (2014). Staged pathology in Parkinson's disease. Parkinsonism Relat. Disord. 20 (Suppl. 1), S57-S61. doi: 10.1016/S1353-8020(13)70016-6

Alexandrov, P. N., Pogue, A., Bhattacharjee, S., and Lukiw, W. J. (2011). Retinal amyloid peptides and complement factor $\mathrm{H}$ in transgenic models of Alzheimer's disease. Neuroreport 22, 623-627. doi: 10.1097/WNR.0b013e3283497334
Neuroinflammatory processes occur not only in the brain but also in the retina, because the retina is a projection of the CNS. Thus AD, PD, and glaucoma share neuroinflammatory changes in the retinal tissue. The follow up of neuroinflammatory processes in the retinal tissue may be useful for the early diagnosis and monitoring of neurodegenerative diseases. Future research could therefore address these issues to provide fuller knowledge of neuroinflammatory events that occur in $\mathrm{AD}, \mathrm{PD}$, and glaucoma, especially the contribution of microglia. This might help in the development of new therapeutic strategies to control neuroinflammation and thereby spur progress in treating these neurodegenerative diseases.

\section{AUTHOR CONTRIBUTIONS}

Conception of the work: Rd, JS, AR, ES, BR, AT, and JR. Acquisition, analysis and interpretation of data for the work: Rd, JS, AR, ES, and JR. Bibliographic research: Rd, JS, AR, ES, DA, PR, IL, and JR. Drafting the work: Rd, JS, AR, ES, DA, IL, and JR. Revising critically for important intellectual content: Rd, JS, AR, ES, DA, IL, PR, BR, AT, and JR. Final approval of the version to be published Rd, JS, AR, ES, IL, DA, PR, BR, AT, and JR. Agreement to be accountable for all aspects of the work in ensuring that questions related to the accuracy or integrity of any part of the work are appropriately investigated and resolved: Rd, JS, AR, ES, DA, IL, PR, BR, AT, and JR.

\section{FUNDING}

This work was supported by the Ophthalmological Network OFTARED (RD16/0008/0005: Enfermedades oculares: "Prevención, detección precoz, tratamiento y rehabilitación de las patologías oculares."), of the Institute of Health of Carlos III of the Spanish Ministry of Economy. This work has been funded by the PN I+D+i 2008-2011, by the ISCIII-Subdirección General de Redes y Centros de Investigación Cooperativa, and by the European programme FEDER. SAF-2014-53779-R: Neuroinflamación en glaucoma: Secuenciación de la alteración glial y de la barrera hematorretiniana. AINES encapsulados en microparticulas de PLGA como terapia neuroprotectora" from the Spanish Ministry of Economy and Competitiveness. Grants to Elena Salobrar-Garcia are currently supported by a Predoctoral Fellowship (FPU) from the Spanish Ministry of Education, Culture and Sport.

\section{ACKNOWLEDGMENTS}

David Nesbitt corrected the English version of this work.

Anderson, J. P., Walker, D. E., Goldstein, J. M., de Laat, R., Banducci, K., Caccavello, R. J., et al. (2006). Phosphorylation of Ser-129 is the dominant pathological modification of alpha-synuclein in familial and sporadic Lewy body disease. J. Biol. Chem. 281, 29739-29752. doi: 10.1074/jbc.M6009 33200

Andreasson, K. I., Bachstetter, A. D., Colonna, M., Ginhoux, F., Holmes, C., Lamb, B., et al. (2016). Targeting innate immunity for neurodegenerative disorders of the central nervous system. J. Neurochem. 138, 653-693. doi: 10.1111/jnc.13667 
Antonucci, F., Turola, E., Riganti, L., Caleo, M., Gabrielli, M., Perrotta, C., et al. (2012). Microvesicles released from microglia stimulate synaptic activity via enhanced sphingolipid metabolism. EMBO J. 31, 1231-1240. doi: 10.1038/emboj.2011.489

Appel, S. H., Beers, D. R., and Henkel, J. S. (2010). T cell-microglial dialogue in Parkinson's disease and amyotrophic lateral sclerosis: are we listening? Trends Immunol. 31, 7-17. doi: 10.1016/j.it.2009.09.003

Astafurov, K., Elhawy, E., Ren, L., Dong, C. Q., Igboin, C., Hyman, L., et al. (2014). Oral microbiome link to neurodegeneration in glaucoma. PLOS ONE 9:e104416. doi: 10.1371/journal.pone.0104416

Beach, T. G., Carew, J., Serrano, G., Adler, C. H., Shill, H. A., Sue, L. I., et al. (2014). Phosphorylated alpha-synuclein-immunoreactive retinal neuronal elements in Parkinson's disease subjects. Neurosci. Lett. 571, 34-38. doi: 10.1016/j.neulet.2014.04.027

Bennett, R. E., DeVos, S. L., Dujardin, S., Corjuc, B., Gor, R., Gonzalez, J., et al. (2017). Enhanced tau aggregation in the presence of Amyloid B. Am. J. Pathol. 187, 1601-1612. doi: 10.1016/j.ajpath.2017.03.011

Bialas, A. R., and Stevens, B. (2013). TGF-beta signaling regulates neuronal C1q expression and developmental synaptic refinement. Nat. Neurosci. 16, 1773-1782. doi: 10.1038/nn.3560

Block, M. L., Zecca, L., and Hong, J. S. (2007). Microglia-mediated neurotoxicity: uncovering the molecular mechanisms. Nat. Rev. Neurosci. 8, 57-69. doi: $10.1038 / \mathrm{nrn} 2038$

Bodis-Wollner, I. (1990). Visual deficits related to dopamine deficiency in experimental animals and Parkinson's disease patients. Trends Neurosci. 13, 296-302. doi: 10.1016/0166-2236(90)90113-O

Bodis-Wollner, I., Kozlowski, P. B., Glazman, S., and Miri, S. (2014). AlphaSynuclein in the inner retina in Parkinson disease. Ann. Neurol. 75, 964-966. doi: $10.1002 /$ ana.24182

Boeke, A., Rosen, D., Mastrianni, J., Xie, T., and Bernard, J. (2016). Optical coherence tomography as potential biomarker in Parkinson's disease and Alzheimer's disease (P5. 177). Neurology 86(16 Suppl.), P5. 177.

Bolos, M., Perea, J. R., and Avila, J. (2017). Alzheimer's disease as an inflammatory disease. Biomol. Concepts 8, 37-43. doi: 10.1515/bmc-2016-0029

Bosco, A., Breen, K. T., Anderson, S. R., Steele, M. R., Calkins, D. J., and Vetter, M. L. (2016). Glial coverage in the optic nerve expands in proportion to optic axon loss in chronic mouse glaucoma. Exp. Eye Res. 150, 34-43. doi: 10.1016/j.exer.2016.01.014

Bosco, A., Crish, S. D., Steele, M. R., Romero, C. O., Inman, D. M., Horner, P. J., et al. (2012). Early reduction of microglia activation by irradiation in a model of chronic glaucoma. PLoS ONE 7:e43602. doi: 10.1371/journal.pone.0043602

Bosco, A., Inman, D. M., Steele, M. R., Wu, G., Soto, I., Marsh-Armstrong, N., et al. (2008). Reduced retina microglial activation and improved optic nerve integrity with minocycline treatment in the DBA/2J mouse model of glaucoma. Invest. Ophthalmol. Vis. Sci. 49, 1437-1446. doi: 10.1167/iovs.07-1337

Bosco, A., Steele, M. R., and Vetter, M. L. (2011). Early microglia activation in a mouse model of chronic glaucoma. J. Comp. Neurol. 519, 599-620. doi: 10.1002/cne.22516

Braak, H., Del Tredici, K., Rub, U., de Vos, R. A., Jansen Steur, E. N., and Braak, E. (2003). Staging of brain pathology related to sporadic Parkinson's disease. Neurobiol. Aging 24, 197-211. doi: 10.1016/S0197-4580(02)00065-9

Breen, K. T., Anderson, S. R., Steele, M. R., Calkins, D. J., Bosco, A., and Vetter, M. L. (2016). Loss of fractalkine signaling exacerbates axon transport dysfunction in a chronic model of glaucoma. Front. Neurosci. 10:526. doi: 10.3389/fnins.2016.00526

Broderick, C., Duncan, L., Taylor, N., and Dick, A. D. (2000). IFN-gamma and LPSmediated IL-10-dependent suppression of retinal microglial activation. Invest. Ophthalmol. Vis. Sci. 41, 2613-2622.

Brown, G. C., and Neher, J. J. (2014). Microglial phagocytosis of live neurons. Nat. Rev. Neurosci. 15, 209-216. doi: 10.1038/nrn3710

Brown, G. C., and Vilalta, A. (2015). How microglia kill neurons. Brain Res. 1628(Pt B), 288-297. doi: 10.1016/j.brainres.2015.08.031

Burguillos, M. A., Deierborg, T., Kavanagh, E., Persson, A., Hajji, N., GarciaQuintanilla, A., et al. (2011). Caspase signalling controls microglia activation and neurotoxicity. Nature 472, 319-324. doi: 10.1038/nature09788

Cagnin, A., Brooks, D. J., Kennedy, A. M., Gunn, R. N., Myers, R., Turkheimer, F. E., et al. (2001). In-vivo measurement of activated microglia in dementia. Lancet 358, 461-467. doi: 10.1016/S0140-6736(01)05625-2
Calabrese, V., Scapagnini, G., Giuffrida Stella, A. M., Bates, T. E., and Clark, J. B. (2001). Mitochondrial involvement in brain function and dysfunction: relevance to aging, neurodegenerative disorders and longevity. Neurochem. Res. 26, 739-764. doi: 10.1023/A:1010955807739

Calsolaro, V., and Edison, P. (2016). Neuroinflammation in Alzheimer's disease: current evidence and future directions. Alzheimers Dement. 12, 719-732. doi: 10.1016/j.jalz.2016.02.010

Campello, L., Esteve-Rudd, J., Cuenca, N., and Martin-Nieto, J. (2013). The ubiquitin-proteasome system in retinal health and disease. Mol. Neurobiol. 47, 790-810. doi: 10.1007/s12035-012-8391-5

Cao, S., Standaert, D. G., and Harms, A. S. (2012). The gamma chain subunit of $\mathrm{Fc}$ receptors is required for alpha-synuclein-induced proinflammatory signaling in microglia. J. Neuroinflammat. 9, 259-2094-9-259. doi: 10.1186/1742-2094-9-259

Chang, R. C., Hudson, P., Wilson, B., Haddon, L., and Hong, J. S. (2000). Influence of neurons on lipopolysaccharide-stimulated production of nitric oxide and tumor necrosis factor-alpha by cultured glia. Brain Res. 853, 236-244. doi: 10.1016/S0006-8993(99)02255-6

Chao, Y., Wong, S. C., and Tan, E. K. (2014). Evidence of inflammatory system involvement in Parkinson's disease. Biomed Res. Int. 2014:308654. doi: 10.1155/2014/308654

Chen, S. T., Hsu, J. R., Hsu, P. C., and Chuang, J. I. (2003). The retina as a novel in vivo model for studying the role of molecules of the $\mathrm{Bcl}-$ 2 family in relation to MPTP neurotoxicity. Neurochem. Res. 28, 805-814. doi: 10.1023/A:1023298604347

Cherry, J. D., Olschowka, J. A., and O'Banion, M. K. (2014). Neuroinflammation and M2 microglia: the good, the bad, and the inflamed. J. Neuroinflammat. 11:98. doi: 10.1186/1742-2094-11-98

Chiarini, A., Armato, U., Liu, D., and Dal Pra, I. (2016). Calcium-sensing receptors of human neural cells play crucial roles in Alzheimer's disease. Front. Physiol. 7:134. doi: $10.3389 /$ fphys.2016.00134

Chidlow, G., Ebneter, A., Wood, J. P., and Casson, R. J. (2016). Evidence supporting an association between expression of major histocompatibility complex II by microglia and optic nerve degeneration during experimental glaucoma. $J$. Glaucoma 25, 681-691. doi: 10.1097/IJG.0000000000000447

Cho, K. I., Searle, K., Webb, M., Yi, H., and Ferreira, P. A. (2012). Ranbp2 haploinsufficiency mediates distinct cellular and biochemical phenotypes in brain and retinal dopaminergic and glia cells elicited by the Parkinsonian neurotoxin, 1-methyl-4-phenyl-1,2,3,6-tetrahydropyridine (MPTP). Cell. Mol. Life Sci. 69, 3511-3527. doi: 10.1007/s00018-012-1071-9

Chrysostomou, V., Rezania, F., Trounce, I. A., and Crowston, J. G. (2013). Oxidative stress and mitochondrial dysfunction in glaucoma. Curr. Opin. Pharmacol. 13, 12-15. doi: 10.1016/j.coph.2012.09.008

Clark, A. K., Gruber-Schoffnegger, D., Drdla-Schutting, R., Gerhold, K. J., Malcangio, M., and Sandkuhler, J. (2015). Selective activation of microglia facilitates synaptic strength. J. Neurosci. 35, 4552-4570. doi: 10.1523/JNEUROSCI.2061-14.2015

Conway, K. A., Harper, J. D., and Lansbury, P. T. (1998). Accelerated in vitro fibril formation by a mutant alpha-synuclein linked to early-onset Parkinson disease. Nat. Med. 4, 1318-1320. doi: 10.1038/3311

Cosenza-Nashat, M., Zhao, M. L., Suh, H. S., Morgan, J., Natividad, R., Morgello, S., et al. (2009). Expression of the translocator protein of $18 \mathrm{kDa}$ by microglia, macrophages and astrocytes based on immunohistochemical localization in abnormal human brain. Neuropathol. Appl. Neurobiol. 35, 306-328. doi: 10.1111/j.1365-2990.2008.01006.x

Cuenca, N., Fernández-Sánchez, L., Campello, L., Maneu, V., De la Villa, P., Lax, P., et al. (2014). Cellular responses following retinal injuries and therapeutic approaches for neurodegenerative diseases. Prog. Retin. Eye Res. 43, 17-75. doi: 10.1016/j.preteyeres.2014.07.001

Cuenca, N., Herrero, M. T., Angulo, A., de Juan, E., Martinez-Navarrete, G. C., Lopez, S., et al. (2005). Morphological impairments in retinal neurons of the scotopic visual pathway in a monkey model of Parkinson's disease. J. Comp. Neurol. 493, 261-273. doi: 10.1002/cne.20761

da Fonseca, A. C., Matias, D., Garcia, C., Amaral, R., Geraldo, L. H., Freitas, C., et al. (2014). The impact of microglial activation on blood-brain barrier in brain diseases. Front. Cell Neurosci. 8:362. doi: 10.3389/fncel.2014.00362

D'Andrea, M. R. (2005). Add Alzheimer's disease to the list of autoimmune diseases. Med. Hypotheses 64, 458-463. doi: 10.1016/j.mehy.2004.08.024 
Danesh-Meyer, H. V., Birch, H., Ku, J. Y., Carroll, S., and Gamble, G. (2006). Reduction of optic nerve fibers in patients with Alzheimer disease identified by laser imaging. Neurology 67, 1852-1854. doi: 10.1212/01.wnl.0000244490.07925.8b

Dauer, W., and Przedborski, S. (2003). Parkinson's disease: mechanisms and models. Neuron 39, 889-909. doi: 10.1016/s0896-6273(03)00568-3

de Hoz, R., Gallego, B. I., Ramírez, A. I., Rojas, B., Salazar, J. J., Valiente-Soriano, F. J., et al. (2013). Rod-like microglia are restricted to eyes with laser-induced ocular hypertension but absent from the microglial changes in the contralateral untreated eye. PLoS ONE 8:e83733. doi: 10.1371/journal.pone.0083733

de Hoz, R., Rojas, B., Ramirez, A. I., Salazar, J. J., Gallego, B. I., Trivino, A., et al. (2016). Retinal Macroglial Responses in Health and Disease. Biomed. Res. Int. 2016:2954721. doi: 10.1155/2016/2954721

de Lau, L. M., and Breteler, M. M. (2006). Epidemiology of Parkinson's disease. Lancet Neurol 5, 525-535. doi: 10.1016/S1474-4422(06)70471-9

De Strooper, B., and Karran, E. (2016). The cellular phase of Alzheimer's disease. Cell 164, 603-615. doi: 10.1016/j.cell.2015.12.056

Deane, R., Singh, I., Sagare, A. P., Bell, R. D., Ross, N. T., LaRue, B., et al. (2012). A multimodal RAGE-specific inhibitor reduces amyloid beta-mediated brain disorder in a mouse model of Alzheimer disease. J. Clin. Invest. 122, 1377-1392. doi: 10.1172/JCI58642

Ding, Y. M., Jaumotte, J. D., Signore, A. P., and Zigmond, M. J. (2004). Effects of 6hydroxydopamine on primary cultures of substantia nigra: specific damage to dopamine neurons and the impact of glial cell line-derived neurotrophic factor. J. Neurochem. 89, 776-787. doi: 10.1111/j.1471-4159.2004.02415.x

Djamgoz, M. B., Hankins, M. W., Hirano, J., and Archer, S. N. (1997). Neurobiology of retinal dopamine in relation to degenerative states of the tissue. Vision Res. 37, 3509-3529. doi: 10.1016/S0042-6989(97)00129-6

Doorn, K. J., Moors, T., Drukarch, B., van de Berg, W. D., Lucassen, P. J., and van Dam, A. M. (2014). Microglial phenotypes and toll-like receptor 2 in the substantia nigra and hippocampus of incidental Lewy body disease cases and Parkinson's disease patients. Acta Neuropathol. Commun. 2:90-014-0090-1. doi: 10.1186/s40478-014-0090-1

Dudvarski Stankovic, N., Teodorczyk, M., Ploen, R., Zipp, F., and Schmidt, M. H. (2016). Microglia-blood vessel interactions: a double-edged sword in brain pathologies. Acta Neuropathol. 131, 347-363. doi: 10.1007/s00401-015-1524-y

Ebneter, A., Casson, R. J., Wood, J. P., and Chidlow, G. (2010). Microglial activation in the visual pathway in experimental glaucoma: spatiotemporal characterization and correlation with axonal injury. Invest. Ophthalmol. Vis. Sci. 51, 6448-6460. doi: 10.1167/iovs.10-5284

Esteve-Rudd, J., Fernandez-Sanchez, L., Lax, P., De Juan, E., Martin-Nieto, J., and Cuenca, N. (2011). Rotenone induces degeneration of photoreceptors and impairs the dopaminergic system in the rat retina. Neurobiol. Dis. 44, 102-115. doi: 10.1016/j.nbd.2011.06.009

Fakhoury, M. (2016). Immune-mediated processes in neurodegeneration: where do we stand? J. Neurol. 263, 1683-1701. doi: 10.1007/s00415-016-8052-0

Fallon, M., Valero, O., Pazos, M., and Antón, A. (2017). Diagnostic accuracy of imaging devices in glaucoma: a meta-analysis. Surv. Ophthalmol. 62, 446-461. doi: 10.1016/j.survophthal.2017.01.001

Farina, C., Aloisi, F., and Meinl, E. (2007). Astrocytes are active players in cerebral innate immunity. Trends Immunol. 28, 138-145. doi: 10.1016/j.it.2007.01.005

Fellner, L., Irschick, R., Schanda, K., Reindl, M., Klimaschewski, L., Poewe, W., et al. (2013). Toll-like receptor 4 is required for $\alpha$-synuclein dependent activation of microglia and astroglia. Glia 61, 349-360. doi: 10.1002/glia.22437

Fu, R., Shen, Q., Xu, P., Luo, J. J., and Tang, Y. (2014). Phagocytosis of microglia in the central nervous system diseases. Mol. Neurobiol. 49, 1422-1434. doi: 10.1007/s12035-013-8620-6

Gallego, B. I., Salazar, J. J., de Hoz, R., Rojas, B., Ramírez, A. I., SalinasNavarro, M., et al. (2012). IOP induces upregulation of GFAP and MHC-II and microglia reactivity in mice retina contralateral to experimental glaucoma. $J$. Neuroinflammat. 9:92. doi: 10.1186/1742-2094-9-92

Garcia-Martin, E. S., Rojas, B., Ramirez, A. I., de Hoz, R., Salazar, J. J., Yubero, R., et al. (2014). Macular thickness as a potential biomarker of mild Alzheimer's disease. Ophthalmology 121, 1149-1151.e3. doi: 10.1016/j.ophtha.2013.12.023

Garcia-Ospina, G. P., Jimenez-Del Rio, M., Lopera, F., and Velez-Pardo, C. (2003). Neuronal DNA damage correlates with a positive detection of c-Jun, nuclear factor kB, p53 and Par-4 transcription factors in Alzheimer's disease. Rev. Neurol 36, 1004-1010.
Garden, G. A., and Möller, T. (2006). Microglia biology in health and disease. J. Neuroimmune Pharmacol. 1, 127-137. doi: 10.1007/s11481-006-9015-5

Garlanda, C., Dinarello, C. A., and Mantovani, A. (2013). The interleukin-1 family: back to the future. Immunity 39, 1003-1018. doi: 10.1016/j.immuni.2013.11.010

Gasparini, L., Crowther, R. A., Martin, K. R., Berg, N., Coleman, M., Goedert, M., et al. (2011). Tau inclusions in retinal ganglion cells of human P301S tau transgenic mice: effects on axonal viability. Neurobiol. Aging 32, 419-433. doi: 10.1016/j.neurobiolaging.2009.03.002

Gazulla, J., and Cavero-Nagore, M. (2006). Glutamate and Alzheimer's disease. Rev. Neurol 42, 427-432.

George, S., and Brundin, P. (2015). Immunotherapy in Parkinson's disease: micromanaging Alpha-Synuclein aggregation. J. Parkinsons Dis. 5, 413-424. doi: $10.3233 /$ JPD-150630

Ghiso, J. A., Doudevski, I., Ritch, R., and Rostagno, A. A. (2013). Alzheimer's disease and glaucoma: mechanistic similarities and differences. J. Glaucoma 22(Suppl. 5), S36-S38. doi: 10.1097/IJG.0b013e3182934af6

Giasson, B. I., Duda, J. E., Murray, I. V., Chen, Q., Souza, J. M., Hurtig, H. I., et al. (2000). Oxidative damage linked to neurodegeneration by selective alpha-synuclein nitration in synucleinopathy lesions. Science 290, 985-989. doi: $10.1126 /$ science.290.5493.985

Giulian, D., and Ingeman, J. E. (1988). Colony-stimulating factors as promoters of ameboid microglia. J. Neurosci. 8, 4707-4717.

Glass, C. K., Saijo, K., Winner, B., Marchetto, M. C., and Gage, F. H. (2010). Mechanisms underlying inflammation in neurodegeneration. Cell 140, 918-934. doi: 10.1016/j.cell.2010.02.016

Glezer, I., Simard, A. R., and Rivest, S. (2007). Neuroprotective role of the innate immune system by microglia. Neuroscience 147, 867-883. doi: 10.1016/j.neuroscience.2007.02.055

Gold, M., and El Khoury, J. (2015). beta-amyloid, microglia, and the inflammasome in Alzheimer's disease. Semin. Immunopathol. 37, 607-611. doi: 10.1007/s00281-015-0518-0

Goldblum, D., Kipfer-Kauer, A., Sarra, G. M., Wolf, S., and Frueh, B. E. (2007). Distribution of amyloid precursor protein and amyloid-beta immunoreactivity in DBA/2J glaucomatous mouse retinas. Invest. Ophthalmol. Vis. Sci. 48, 5085-5090. doi: 10.1167/iovs.06-1249

Gonzalez, H., Contreras, F., and Pacheco, R. (2015). Regulation of the neurodegenerative process associated to Parkinson's disease by CD4+ T-cells. J. Neuroimmune Pharmacol. 10, 561-575. doi: 10.1007/s11481-015-9618-9

Gonzalez, H., Elgueta, D., Montoya, A., and Pacheco, R. (2014). Neuroimmune regulation of microglial activity involved in neuroinflammation and neurodegenerative diseases. J. Neuroimmunol. 274, 1-13. doi: 10.1016/j.jneuroim.2014.07.012

Gordon, R., Anantharam, V., Kanthasamy, A. G., and Kanthasamy, A. (2012). Proteolytic activation of proapoptotic kinase protein kinase Cdelta by tumor necrosis factor alpha death receptor signaling in dopaminergic neurons during neuroinflammation. J. Neuroinflammat. 9, 1-18. doi: 10.1186/1742-20 94-9-82

Graeber, M. B., and Streit, W. J. (2010). Microglia: biology and pathology. Acta Neuropathol. 119, 89-105. doi: 10.1007/s00401-009-0622-0

Gramlich, O. W., Beck, S., von Hohenstein-Blaul, N., Boehm, N., Ziegler, A., Vetter, J. M., et al. (2013). Enhanced insight into the autoimmune component of glaucoma: IgG autoantibody accumulation and proinflammatory conditions in human glaucomatous retina. PLOS ONE 8:e57557. doi: 10.1371/journal.pone.0057557

Grus, F. H., Joachim, S. C., Wuenschig, D., Rieck, J., and Pfeiffer, N. (2008). Autoimmunity and glaucoma. J. Glaucoma 17, 79-84. doi: 10.1097/IJG.0b013e318156a592

Guerriero, F., Sgarlata, C., Francis, M., Maurizi, N., Faragli, A., Perna, S., et al. (2016). Neuroinflammation, immune system and Alzheimer disease: searching for the missing link. Aging Clin. Exp. Res. doi: 10.1007/s40520-016-0637-z. [Epub ahead of print].

Guimaraes, J. S., Freire, M. A., Lima, R. R., Souza-Rodrigues, R. D., Costa, A. M. dos Santos, C. D., et al. (2009). Mechanisms of secondary degeneration in the central nervous system during acute neural disorders and white matter damage. Rev. Neurol. 48, 304-310.

Gupta, N., Ang, L. C., Noel de Tilly, L., Bidaisee, L., and Yucel, Y. H. (2006). Human glaucoma and neural degeneration in intracranial optic nerve, 
lateral geniculate nucleus, and visual cortex. Br. J. Ophthalmol. 90, 674-678. doi: 10.1136/bjo.2005.086769

Gupta, N., Fong, J., Ang, L. C., and Yucel, Y. H. (2008). Retinal tau pathology in human glaucomas. Can. J. Ophthalmol. 43, 53-60. doi: 10.3129/i07-185

Gupta, N., Ly, T., Zhang, Q., Kaufman, P. L., Weinreb, R. N., and Yucel, Y. H. (2007). Chronic ocular hypertension induces dendrite pathology in the lateral geniculate nucleus of the brain. Exp. Eye Res. 84, 176-184. doi: $10.1016 /$ j.exer.2006.09.013

Hajee, M. E., March, W. F., Lazzaro, D. R., Wolintz, A. H., Shrier, E. M., Glazman, S., et al. (2009). Inner retinal layer thinning in Parkinson disease. Arch. Ophthalmol. 127, 737-741. doi: 10.1001/archophthalmol.2009.106

Hammam, T., Montgomery, D., Morris, D., and Imrie, F. (2008). Prevalence of serum autoantibodies and paraproteins in patients with glaucoma. Eye (Lond). 22, 349-353. doi: 10.1038/sj.eye.6702613

Hamza, T. H., Zabetian, C. P., Tenesa, A., Laederach, A., Montimurro, J., Yearout, D., et al. (2010). Common genetic variation in the HLA region is associated with late-onset sporadic Parkinson's disease. Nat. Genet. 42, 781-785. doi: 10.1038/ng.642

Han, J., Wang, M., Ren, M., and Lou, H. (2017). Contributions of triggeringreceptor-expressed-on-myeloid-cells-2 to neurological diseases. Int. J. Neurosci. 127, 368-375. doi: 10.1080/00207454.2016.1264072

Hanisch, U. K., and Kettenmann, H. (2007). Microglia: active sensor and versatile effector cells in the normal and pathologic brain. Nat. Neurosci. 10, 1387-1394. doi: $10.1038 / \mathrm{nn} 1997$

Hardy, J., and Selkoe, D. J. (2002). The amyloid hypothesis of Alzheimer's disease: progress and problems on the road to therapeutics. Science 297, 353-356. doi: $10.1126 /$ science. 1072994

Harms, A. S., Cao, S., Rowse, A. L., Thome, A. D., Li, X., Mangieri, L. R., et al. (2013). MHCII is required for alpha-synuclein-induced activation of microglia, CD4 T cell proliferation, and dopaminergic neurodegeneration. J. Neurosci. 33, 9592-9600. doi: 10.1523/JNEUROSCI.5610-12.2013

Hart, N. J., Koronyo, Y., Black, K. L., and Koronyo-Hamaoui, M. (2016). Ocular indicators of Alzheimer's: exploring disease in the retina. Acta Neuropathol. 132, 767-787. doi: 10.1007/s00401-016-1613-6

Hatfield, C. F., Herbert, J., van Someren, E. J., Hodges, J. R., and Hastings, M. H. (2004). Disrupted daily activity/rest cycles in relation to daily cortisol rhythms of home-dwelling patients with early Alzheimer's dementia. Brain 127(Pt 5), 1061-1074. doi: 10.1093/brain/awh129

Hedges, T. R., III, Perez Galves, R., Speigelman, D., Barbas, N. R., Peli, E., et al. (1996). Retinal nerve fiber layer abnormalities in Alzheimer's disease. Acta Ophthalmol. Scand. 74, 271-275. doi: 10.1111/j.1600-0420.1996.tb00090.x

Heneka, M. T., Carson, M. J., El Khoury, J., Landreth, G. E., Brosseron, F., Feinstein, D. L., et al. (2015). Neuroinflammation in Alzheimer's disease. Lancet Neurol. 14, 388-405. doi: 10.1016/S1474-4422(15)70016-5

Heneka, M. T., Kummer, M. P., Stutz, A., Delekate, A., Schwartz, S., Vieira-Saecker, A., et al. (2013). NLRP3 is activated in Alzheimer's disease and contributes to pathology in APP/PS1 mice. Nature 493, 674-678. doi: 10.1038/nature11729

Hernández-Montiel, H. L. (2006). Aspectos moleculares y prospectos de terapias en la enfermedad de Parkinson. Bioquimia 31, 146-158.

Herrera, A. J., Espinosa-Oliva, A. M., Carrillo-Jimenez, A., Oliva-Martin, M. J., Garcia-Revilla, J., Garcia-Quintanilla, A., et al. (2015). Relevance of chronic stress and the two faces of microglia in Parkinson's disease. Front. Cell Neurosci. 9:312. doi: 10.3389/fncel.2015.00312

Holcomb, L., Gordon, M. N., McGowan, E., Yu, X., Benkovic, S., Jantzen, P., et al. (1998). Accelerated Alzheimer-type phenotype in transgenic mice carrying both mutant amyloid precursor protein and presenilin 1 transgenes. Nat. Med. 4, 97-100. doi: 10.1038/nm0198-097

Hong, S., Dissing-Olesen, L., and Stevens, B. (2016). New insights on the role of microglia in synaptic pruning in health and disease. Curr. Opin. Neurobiol. 36, 128-134. doi: 10.1016/j.conb.2015.12.004

Hooghiemstra, A. M., Eggermont, L. H., Scheltens, P., van der Flier, W. M., and Scherder, E. J. (2015). The rest-activity rhythm and physical activity in early-onset dementia. Alzheimer Dis. Assoc. Disord 29, 45-49. doi: 10.1097/WAD.0000000000000037

Howell, G. R., Soto, I., Zhu, X., Ryan, M., Macalinao, D. G., Sousa, G. L., et al. (2012). Radiation treatment inhibits monocyte entry into the optic nerve head and prevents neuronal damage in a mouse model of glaucoma. J. Clin. Invest. 122, 1246-1261. doi: 10.1172/JCI61135
Hsiao, K., Chapman, P., Nilsen, S., Eckman, C., Harigaya, Y., Younkin, S., et al. (1996). Correlative memory deficits, Abeta elevation, and amyloid plaques in transgenic mice. Science 274, 99-102.

Hsieh, C. L., Koike, M., Spusta, S. C., Niemi, E. C., Yenari, M., Nakamura, M. C., et al. (2009). A role for TREM2 ligands in the phagocytosis of apoptotic neuronal cells by microglia. J. Neurochem. 109, 1144-1156. doi: $10.1111 / j .1471-4159.2009 .06042 . x$

Inman, D. M., and Horner, P. J. (2007). Reactive nonproliferative gliosis predominates in a chronic mouse model of glaucoma. Glia 55, 942-953. doi: $10.1002 /$ glia.20516

Inzelberg, R., Ramirez, J. A., Nisipeanu, P., and Ophir, A. (2004). Retinal nerve fiber layer thinning in Parkinson disease. Vision Res. 44, 2793-2797. doi: $10.1016 /$ j.visres.2004.06.009

Iseri, P. K., Altinas, O., Tokay, T., and Yuksel, N. (2006). Relationship between cognitive impairment and retinal morphological and visual functional abnormalities in Alzheimer disease. J. Neuroophthalmol. 26, 18-24. doi: 10.1097/01.wno.0000204645.56873.26

Jack, C. S., Arbour, N., Manusow, J., Montgrain, V., Blain, M., McCrea, E., et al. (2005). TLR signaling tailors innate immune responses in human microglia and astrocytes. J. Immunol. 175, 4320-4330. doi: 10.4049/jimmunol.175.7.4320

Johnson, E. C., Jia, L., Cepurna, W. O., Doser, T. A., and Morrison, J. C. (2007). Global changes in optic nerve head gene expression after exposure to elevated intraocular pressure in a rat glaucoma model. Invest. Ophthalmol. Vis. Sci. 48, 3161-3177. doi: $10.1167 /$ iovs.06-1282

Jones, E. V., and Bouvier, D. S. (2014). Astrocyte-secreted matricellular proteins in CNS remodelling during development and disease. Neural Plast. 2014:321209. doi: $10.1155 / 2014 / 321209$

Jonsson, T., Stefansson, H., Steinberg, S., Jonsdottir, I., Jonsson, P. V., Snaedal, J., et al. (2013). Variant of TREM2 associated with the risk of Alzheimer's disease. N. Engl. J. Med. 368, 107-116. doi: 10.1056/NEJMoa1211103

Kaarniranta, K., Salminen, A., Haapasalo, A., Soininen, H., and Hiltunen, M. (2011). Age-related macular degeneration (AMD): Alzheimer's disease in the eye? J. Alzheimer's Dis. 24, 615-631. doi: 10.3233/JAD-2011-101908

Kannarkat, G. T., Boss, J. M., and Tansey, M. G. (2013). The role of innate and adaptive immunity in Parkinson's disease. J. Parkinsons Dis. 3, 493-514. doi: 10.3233/JPD-130250

Karlstetter, M., Ebert, S., and Langmann, T. (2010). Microglia in the healthy and degenerating retina: Insights from novel mouse models. Immunobiology 215, 685-691. doi: 10.1016/j.imbio.2010.05.010

Karlstetter, M., Scholz, R., Rutar, M., Wong, W. T., Provis, J. M., and Langmann, T. (2015). Retinal microglia: just bystander or target for therapy? Prog. Retin. Eye Res. 45, 30-57. doi: 10.1016/j.preteyeres.2014. 11.004

Kayabasi, U., Sergott, R. C., and Rispoli, M. (2014). Retinal examination for the diagnosis of Alzheimer's disease. Int. J. Ophthal. Pathol. 3:4. doi: 10.4172/2324-8599.1000145

Kesler, A., Vakhapova, V., Korczyn, A. D., Naftaliev, E., and Neudorfer, M. (2011). Retinal thickness in patients with mild cognitive impairment and Alzheimer's disease. Clin. Neurol Neurosurg. 113, 523-526. doi: 10.1016/j.clineuro.2011.02.014

Kettenmann, H., Hanisch, U., Noda, M., and Verkhratsky, A. (2011). Physiology of Microglia. Physiol. Rev. 91, 461-553. doi: 10.1152/physrev.00011.2010

Kim, S. R., Chung, E. S., Bok, E., Baik, H. H., Chung, Y. C., Won, S. Y., et al. (2010). Prothrombin kringle-2 induces death of mesencephalic dopaminergic neurons in vivo and in vitro via microglial activation. J. Neurosci. Res. 88, 1537-1548. doi: $10.1002 / j n r .22318$

Kingsbury, A. E., Daniel, S. E., Sangha, H., Eisen, S., Lees, A. J., and Foster, O. J. (2004). Alteration in alpha-synuclein mRNA expression in Parkinson's disease. Mov. Disord. 19, 162-170. doi: 10.1002/mds.10683

Koizumi, S., Shigemoto-Mogami, Y., Nasu-Tada, K., Shinozaki, Y., Ohsawa, K., Tsuda, M., et al. (2007). UDP acting at P2Y6 receptors is a mediator of microglial phagocytosis. Nature 446, 1091-1095. doi: 10.1038/nature05704

Komori, T., Morikawa, Y., Inada, T., Hisaoka, T., and Senba, E. (2011). Site-specific subtypes of macrophages recruited after peripheral nerve injury. Neuroreport 22, 911-917. doi: 10.1097/WNR.0b013e32834cd76a

Koronyo-Hamaoui, M., Koronyo, Y., Ljubimov, A. V., Miller, C. A., Ko, M. K., Black, K. L., et al. (2011). Identification of amyloid plaques in retinas from Alzheimer's patients and noninvasive in vivo optical imaging 
of retinal plaques in a mouse model. Neuroimage 54(Suppl. 1), S204-S217. doi: 10.1016/j.neuroimage.2010.06.020

Krasodomska, K., Lubinski, W., Potemkowski, A., and Honczarenko, K. (2010). Pattern electroretinogram (PERG) and pattern visual evoked potential (PVEP) in the early stages of Alzheimer's disease. Doc. Ophthalmol. 121, 111-121. doi: 10.1007/s10633-010-9238-x

Kreutzberg, G. (1995). Microglia, the first line of defence in brain pathologies. Arzneimittelforschung 45, 357-360.

Kreutzberg, G. W. (1996). Microglia: a sensor for pathological events in the CNS. Trends Neurosci. 19, 312-318. doi: 10.1016/0166-2236(96)10049-7

Kumar-Singh, S., Pirici, D., McGowan, E., Serneels, S., Ceuterick, C., Hardy, J., et al. (2005). Dense-core plaques in Tg2576 and PSAPP mouse models of Alzheimer's disease are centered on vessel walls. Am. J. Pathol. 167, 527-543. doi: 10.1016/S0002-9440(10)62995-1

Kummer, M. P., Hermes, M., Delekarte, A., Hammerschmidt, T., Kumar, S., Terwel, D., et al. (2011). Nitration of tyrosine 10 critically enhances amyloid beta aggregation and plaque formation. Neuron 71, 833-844. doi: 10.1016/j.neuron.2011.07.001

La Morgia, C., Barboni, P., Rizzo, G., Carbonelli, M., Savini, G., Scaglione, C., et al. (2013). Loss of temporal retinal nerve fibers in Parkinson disease: a mitochondrial pattern? Eur. J. Neurol. 20, 198-201. doi: 10.1111/j.1468-1331.2012.03701.x

La Morgia, C., Ross-Cisneros, F. N., Hannibal, J., Montagna, P., Sadun, A. A., and Carelli, V. (2011). Melanopsin-expressing retinal ganglion cells: implications for human diseases. Vision Res. 51, 296-302. doi: 10.1016/j.visres.2010.07.023

Lakey-Beitia, J., González, Y., Doens, D., Stephens, D. E., Santamaría, R., Murillo, E., et al. (2017). Assessment of novel curcumin derivatives as potent inhibitors of inflammation and Amyloid- $\beta$ aggregation in Alzheimer's disease. J. Alzheimer's Dis. doi: 10.3233/JAD-170071. [Epub ahead of print].

Langmann, T. (2007). Microglia activation in retinal degeneration. J. Leukoc. Biol. 81, 1345-1351. doi: 10.1189/jlb.0207114

Lascaratos, G., Garway-Heath, D. F., Willoughby, C. E., Chau, K., and Schapira, A. H. V. (2012). Mitochondrial dysfunction in glaucoma: understanding genetic influences. Mitochondrion 12, 202-212. doi: 10.1016/j.mito.2011.11.004

Lauro, C., Cipriani, R., Catalano, M., Trettel, F., Chece, G., Brusadin, V., et al. (2010). Adenosine A1 receptors and microglial cells mediate CX3CL1induced protection of hippocampal neurons against Glu-induced death. Neuropsychopharmacology 35, 1550-1559. doi: 10.1038/npp.2010.26

Lauro, C., Di Angelantonio, S., Cipriani, R., Sobrero, F., Antonilli, L., Brusadin, V., et al. (2008). Activity of adenosine receptors type 1 Is required for CX3CL1mediated neuroprotection and neuromodulation in hippocampal neurons. $J$. Immunol. 180, 7590-7596. doi: 10.4049/jimmunol.180.11.7590

Le, W., Wu, J., and Tang, Y. (2016). Protective microglia and their regulation in Parkinson's disease. Front. Mol. Neurosci. 9:89. doi: 10.3389/fnmol.2016.00089

Lee, J., Shin, J., Chun, M., and Oh, S. (2014). Morphological analyses on retinal glial responses to glaucomatous injury evoked by venous cauterization. Appl. Microsc. 44, 21-29. doi: 10.9729/AM.2014.44.1.21

Lee, S., Van Bergen, N. J., Kong, G. Y., Chrysostomou, V., Waugh, H. S., O’Neill, E. C., et al. (2011). Mitochondrial dysfunction in glaucoma and emerging bioenergetic therapies. Exp. Eye Res. 93, 204-212. doi: 10.1016/j.exer.2010.07.015

Leem, E., Jeong, K. H., Won, S. Y., Shin, W. H., and Kim, S. R. (2016). Prothrombin Kringle-2: a potential inflammatory pathogen in the parkinsonian dopaminergic system. Exp. Neurobiol. 25, 147-155. doi: 10.5607/en.2016.25.4.147

Leroy, K., Bretteville, A., Schindowski, K., Gilissen, E., Authelet, M., De Decker, R., et al. (2007). Early axonopathy preceding neurofibrillary tangles in mutant tau transgenic mice. Am. J. Pathol. 171, 976-992. doi: 10.2353/ajpath.2007.070345

Leung, C. K. (2016). Optical coherence tomography imaging for glaucoma - today and tomorrow. Asia Pac. J. Ophthalmol. (Phila) 5, 11-16. doi: 10.1097/APO.0000000000000179

Licht, T., and Keshet, E. (2015). The vascular niche in adult neurogenesis. Mech. Dev. 138(Pt 1), 56-62. doi: 10.1016/j.mod.2015.06.001

Liddelow, S. A., Guttenplan, K. A., Clarke, L. E., Bennett, F. C., Bohlen, C. J., Schirmer, L., et al. (2017). Neurotoxic reactive astrocytes are induced by activated microglia. Nature 541, 481-487. doi: 10.1038/nature21029

Lim, C. K., Fernández-Gomez, F. J., Braidy, N., Estrada, C., Costa, C., Costa, S., et al. (2017). Involvement of the kynurenine pathway in the pathogenesis of Parkinson's disease. Prog. Neurobiol. 155, 76-95 doi: 10.1016/j.pneurobio.2015.12.009

Lim, J. K., Li, Q. X., He, Z., Vingrys, A. J., Wong, V. H., Currier, N., et al. (2016). The eye as a biomarker for Alzheimer's disease. Front. Neurosci. 10:536. doi: $10.3389 /$ fnins.2016.00536

Linnartz, B., Kopatz, J., Tenner, A. J., and Neumann, H. (2012). Sialic acid on the neuronal glycocalyx prevents complement $\mathrm{C} 1$ binding and complement receptor-3-mediated removal by microglia. J. Neurosci. 32, 946-952. doi: 10.1523/JNEUROSCI.3830-11.2012

Liu, B., Rasool, S., Yang, Z., Glabe, C. G., Schreiber, S. S., Ge, J., et al. (2009). Amyloid-peptide vaccinations reduce $\{$ beta\}-amyloid plaques but exacerbate vascular deposition and inflammation in the retina of Alzheimer's transgenic mice. Am. J. Pathol. 175, 2099-2110. doi: 10.2353/ajpath.2009.090159

London, A., Itskovich, E., Benhar, I., Kalchenko, V., Mack, M., Jung, S., et al. (2011). Neuroprotection and progenitor cell renewal in the injured adult murine retina requires healing monocyte-derived macrophages. J. Exp. Med. 208, 23-39. doi: $10.1084 /$ jem.20101202

Lukiw, W. J., Gordon, W. C., Rogaev, E. I., Thompson, H., and Bazan, N. G. (2001). Presenilin-2 (PS2) expression up-regulation in a model of retinopathy of prematurity and pathoangiogenesis. Neuroreport 12, 53-57. doi: 10.1097/00001756-200101220-00019

Lull, M. E., and Block, M. L. (2010). Microglial Activation and Chronic Neurodegeneration. Neurotherapeutics 7, 354-365. doi: 10.1016/j.nurt.2010.05.014

Luo, C., Chen, M., and Xu, H. (2011). Complement gene expression and regulation in mouse retina and retinal pigment epithelium/choroid. Mol. Vis. $17,1588-1597$

Luo, X., Ding, J., and Chen, S. (2010). Microglia in the aging brain: relevance to neurodegeneration. Mol. Neurodegen. 5:12. doi: 10.1186/1750-1326-5-12

MacCormick, I. J., Czanner, G., and Faragher, B. (2015). Developing retinal biomarkers of neurological disease: an analytical perspective. Biomark Med. 9, 691-701. doi: 10.2217/bmm.15.17

Madeira, M. H., Boia, R., Santos, P. F., Ambrosio, A. F., and Santiago, A. R. (2015). Contribution of microglia-mediated neuroinflammation to retinal degenerative diseases. Mediat. Inflamm. 2015:673090. doi: 10.1155/2015/ 673090

Madeira, M. H., Ortin-Martinez, A., Nadal-Nicolas, F., Ambrosio, A. F., VidalSanz, M., Agudo-Barriuso, M., et al. (2016). Caffeine administration prevents retinal neuroinflammation and loss of retinal ganglion cells in an animal model of glaucoma. Sci. Rep. 6:27532. doi: 10.1038/srep27532

Magni, P., Ruscica, M., Dozio, E., Rizzi, E., Beretta, G., and Maffei Facino, R. (2012). Parthenolide inhibits the LPS-induced secretion of IL-6 and TNF-alpha and NF-kappaB nuclear translocation in BV-2 microglia. Phytother Res. 26, 1405-1409. doi: 10.1002/ptr.3732

Maiti, P., and Dunbar, G. L. (2016). Rationale for curcumin therapy in Alzheimer's disease. ARC J. Neurosci. 1, 10-16. doi: 10.20431/2456-057X.0103002

Maldonado, R. S., Mettu, P., El-Dairi, M., and Bhatti, M. T. (2015). The application of optical coherence tomography in neurologic diseases. Neurol. Clin. Pract. 5, 460-469. doi: 10.1212/cpj.0000000000000187

Martínez-Lazcano, J. C., Boll-Woehrlen, M. C., Hernández-Melesio, M., RubioOsornio, M., Sánchez-Mendoza, M., and Ríos, C. (2010). Radicales libres y estrés oxidativo en las enfermedades neurodegenerativas. Mensaje Bioquim 34, 43-59.

Martinez-Navarrete, G. C., Martin-Nieto, J., Esteve-Rudd, J., Angulo, A., and Cuenca, N. (2007). Alpha synuclein gene expression profile in the retina of vertebrates. Mol. Vis. 13, 949-961.

Maruyama, I., Ohguro, H., and Ikeda, Y. (2000). Retinal ganglion cells recognized by serum autoantibody against $\gamma$-enolase found in glaucoma patients. Invest. Ophthalmol. Vis. Sci. 41, 1657-1665.

Mattson, M. P. (2000). Apoptosis in neurodegenerative disorders. Nat. Rev. Mol. Cell Biol. 1, 120-129. doi: 10.1038/35040009

Maurage, C. A., Ruchoux, M. M., de Vos, R., Surguchov, A., and Destee, A. (2003). Retinal involvement in dementia with Lewy bodies: a clue to hallucinations? Ann. Neurol. 54, 542-547. doi: 10.1002/ana.10730

McKinnon, S. J. (2003). Glaucoma: ocular Alzheimer's disease. Front. Biosci 8, s1140-s1156. doi: 10.2741/1172

McKinnon, S. J., Lehman, D. M., Kerrigan-Baumrind, L. A., Merges, C. A., Pease, M. E., Kerrigan, D. F., et al. (2002). Caspase activation and amyloid precursor 
protein cleavage in rat ocular hypertension. Invest. Ophthalmol. Vis. Sci. 43, 1077-1087.

McLaughlin, P., Zhou, Y., Ma, T., Liu, J., Zhang, W., Hong, J. S., et al. (2006). Proteomic analysis of microglial contribution to mouse strain-dependent dopaminergic neurotoxicity. Glia 53, 567-582. doi: 10.1002/glia.20294

Menzies, F. M., Henriquez, F. L., Alexander, J., and Roberts, C. W. (2010). Sequential expression of macrophage anti-microbial/inflammatory and wound healing markers following innate, alternative and classical activation. Clin. Exp. Immunol. 160, 369-379. doi: 10.1111/j.1365-2249.2009.04086.x

Meyer-Luehmann, M., and Prinz, M. (2015). Myeloid cells in Alzheimer's disease: culprits, victims or innocent bystanders? Trends Neurosci. 38, 659-668. doi: 10.1016/j.tins.2015.08.011

Michelucci, A., Heurtaux, T., Grandbarbe, L., Morga, E., and Heuschling, P. (2009). Characterization of the microglial phenotype under specific pro-inflammatory and anti-inflammatory conditions: effects of oligomeric and fibrillar amyloidbeta. J. Neuroimmunol. 210, 3-12. doi: 10.1016/j.jneuroim.2009.02.003

Mirzaei, N., Tang, S. P., Ashworth, S., Coello, C., Plisson, C., Passchier, J., et al. (2016). In vivo imaging of microglial activation by positron emission tomography with [(11)C]PBR28 in the 5XFAD model of Alzheimer's disease. Glia 64, 993-1006. doi: 10.1002/glia.22978

Mogi, M., Harada, M., Narabayashi, H., Inagaki, H., Minami, M., and Nagatsu, T. (1996). Interleukin (IL)-1 beta, IL-2, IL-4, IL-6 and transforming growth factor-alpha levels are elevated in ventricular cerebrospinal fluid in juvenile parkinsonism and Parkinson's disease. Neurosci. Lett. 211, 13-16. doi: 10.1016/0304-3940(96)12706-3

Mosharov, E. V., Staal, R. G., Bove, J., Prou, D., Hananiya, A., Markov, D., et al. (2006). Alpha-synuclein overexpression increases cytosolic catecholamine concentration. J. Neurosci. 26, 9304-9311. doi: 10.1523/JNEUROSCI.0519-06.2006

Mosher, K. I., and Wyss-Coray, T. (2014). Microglial dysfunction in brain aging and Alzheimer's disease. Biochem. Pharmacol. 88, 594-604. doi: 10.1016/j.bcp.2014.01.008

Nagel, F., Bahr, M., and Dietz, G. P. (2009). Tyrosine hydroxylase-positive amacrine interneurons in the mouse retina are resistant against the application of various parkinsonian toxins. Brain Res. Bull. 79, 303-309. doi: 10.1016/j.brainresbull.2009.04.010

Nagele, R. G., D'Andrea, M. R., Lee, H., Venkataraman, V., and Wang, H.Y. (2003). Astrocytes accumulate $A \beta 42$ and give rise to astrocytic amyloid plaques in Alzheimer disease brains. Brain Res. 971, 197-209. doi: 10.1016/ S0006-8993(03)02361-8

Nakazawa, T., Nakazawa, C., Matsubara, A., Noda, K., Hisatomi, T., She, H., et al. (2006). Tumor necrosis factor-alpha mediates oligodendrocyte death and delayed retinal ganglion cell loss in a mouse model of glaucoma. J. Neurosci. 26, 12633-12641. doi: 10.1523/JNEUROSCI.2801-06.2006

Naskar, R., Wissing, M., and Thanos, S. (2002). Detection of early neuron degeneration and accompanying microglial responses in the retina of a rat model of glaucoma. Invest. Ophthalmol. Vis. Sci. 43, 2962-2968.

Nelson, A. R., Sweeney, M. D., Sagare, A. P., and Zlokovic, B. V. (2016). Neurovascular dysfunction and neurodegeneration in dementia and Alzheimer's disease. Biochim. Biophys. Acta 1862, 887-900. doi: 10.1016/ j.bbadis.2015.12.016

Neufeld, A. H. (1999). Microglia in the optic nerve head and the region of parapapillary chorioretinal atrophy in glaucoma. Arch. Ophthalmol. 117, 1050-1056. doi: 10.1001/archopht.117.8.1050

Neufeld, A. H., Hernandez, M. R., and Gonzalez, M. (1997). Nitric oxide synthase in the human glaucomatous optic nerve head. Arch. Ophthalmol. 115, 497-503. doi: 10.1001/archopht.1997.01100150499009

Neystat, M., Lynch, T., Przedborski, S., Kholodilov, N., Rzhetskaya, M., and Burke, R. E. (1999). Alpha-synuclein expression in substantia nigra and cortex in Parkinson's disease. Mov. Disord. 14, 417-422. doi: 10.1002/1531-8257(199905)14:3<417::AID-MDS1005>3.0.CO;2-X

Nickells, R. W. (1999). Apoptosis of retinal ganglion cells in glaucoma: an update of the molecular pathways involved in cell death. Surv. Ophthalmol. 43(Suppl. 1), S151-S161. doi: 10.1016/S0039-6257(99)00029-6

Nigro, A., Colombo, F., Casella, G., Finardi, A., Verderio, C., and Furlan, R. (2016). Myeloid extracellular vesicles: messengers from the demented brain. Front. Immunol. 7:17. doi: 10.3389/fimmu.2016.00017
Ning, A., Cui, J., To, E., Ashe, K. H., and Matsubara, J. (2008). Amyloid-beta deposits lead to retinal degeneration in a mouse model of Alzheimer disease. Invest. Ophthalmol. Vis. Sci. 49, 5136-5143. doi: 10.1167/iovs.08-1849

Nowacka, B., Lubinski, W., Honczarenko, K., Potemkowski, A., and Safranow, K. (2014). Ophthalmological features of Parkinson disease. Med. Sci. Monit. 20, 2243-2249. doi: 10.12659/MSM.890861

Oakley, H., Cole, S. L., Logan, S., Maus, E., Shao, P., Craft, J., et al. (2006). Intraneuronal beta-amyloid aggregates, neurodegeneration, and neuron loss in transgenic mice with five familial Alzheimer's disease mutations: potential factors in amyloid plaque formation. J. Neurosci. 26, 10129-10140. doi: 10.1523/JNEUROSCI.1202-06.2006

Oddo, S., Caccamo, A., Shepherd, J. D., Murphy, M. P., Golde, T. E., Kayed, R., et al. (2003). Triple-transgenic model of Alzheimer's disease with plaques and tangles: intracellular Abeta and synaptic dysfunction. Neuron 39, 409-421. doi: 10.1016/s0896-6273(03)00434-3

Ohsawa, K., Irino, Y., Nakamura, Y., Akazawa, C., Inoue, K., and Kohsaka, S. (2007). Involvement of P2X4 and P2Y12 receptors in ATP-induced microglial chemotaxis. Glia 55, 604-616. doi: 10.1002/glia.20489

Olanow, C. W., and Tatton, W. G. (1999). Etiology and pathogenesis of Parkinson's disease. Annu. Rev. Neurosci. 22, 123-144. doi: 10.1146/annurev.neuro.22.1.123

Orr, C. F., Rowe, D. B., and Halliday, G. M. (2002). An inflammatory review of Parkinson's disease. Prog. Neurobiol. 68, 325-340. doi: 10.1016/S0301-0082(02)00127-2

Owen, D. R., and Matthews, P. M. (2011). Imaging brain microglial activation using positron emission tomography and translocator protein-specific radioligands. Int. Rev. Neurobiol. 101, 19-39. doi: 10.1016/B978-0-12-387718-5.00002-X

Painter, M. M., Atagi, Y., Liu, C. C., Rademakers, R., Xu, H., Fryer, J. D., et al. (2015). TREM2 in CNS homeostasis and neurodegenerative disease. Mol. Neurodegener. 10:43-015-0040-9. doi: 10.1186/s13024-015-0040-9

Paolicelli, R. C., Bolasco, G., Pagani, F., Maggi, L., Scianni, M., Panzanelli, P., et al. (2011). Synaptic pruning by microglia is necessary for normal brain development. Science 333, 1456-1458. doi: 10.1126/science.1202529

Paquet, C., Boissonnot, M., Roger, F., Dighiero, P., Gil, R., and Hugon, J. (2007). Abnormal retinal thickness in patients with mild cognitive impairment and Alzheimer's disease. Neurosci. Lett. 420, 97-99. doi: 10.1016/j.neulet.2007.02.090

Park, S., and Ou, Y. (2013). "Neurodegeneration in Glaucoma and Alzheimer's disease," in Recent Advances in Ophthalmology Research, ed G. Dimitrova (New York, NY: Nova Science Publishers), 59.

Parkhurst, C. N., Yang, G., Ninan, I., Savas, J. N., Yates, J. R. III, Lafaille, J. J., et al. (2013). Microglia promote learning-dependent synapse formation through brain-derived neurotrophic factor. Cell 155, 1596-1609. doi: 10.1016/j.cell.2013.11.030

Parnell, M., Guo, L., Abdi, M., and Cordeiro, M. F. (2012). Ocular manifestations of Alzheimer's disease in animal models. Int. J. Alzheimers Dis. 2012:786494. doi: 10.1155/2012/786494

Parpura, V., Heneka, M. T., Montana, V., Oliet, S. H., Schousboe, A., Haydon, P. G., et al. (2012). Glial cells in (patho)physiology. J. Neurochem. 121, 4-27. doi: 10.1111/j.1471-4159.2012.07664.x

Pasqualetti, G., Brooks, D. J., and Edison, P. (2015). The role of neuroinflammation in dementias. Curr. Neurol Neurosci. Rep. 15:17-015-0531-7. doi: 10.1007/s11910-015-0531-7

Pérez, M. A., and Arancibia, S. R. (2007). Estrés oxidativo y neurodegeneración:i causa o consecuencia. Arch. Neurocienc. 12, 45-54.

Perez, S. E., Lumayag, S., Kovacs, B., Mufson, E. J., and Xu, S. (2009). Beta-amyloid deposition and functional impairment in the retina of the APPswe/PS1DeltaE9 transgenic mouse model of Alzheimer's disease. Invest. Ophthalmol. Vis. Sci. 50, 793-800. doi: 10.1167/iovs.08-2384

Philipson, O., Lord, A., Gumucio, A., O'Callaghan, P., Lannfelt, L., and Nilsson, L. N. (2010). Animal models of amyloid-beta-related pathologies in Alzheimer's disease. FEBS J. 277, 1389-1409. doi: 10.1111/j.1742-4658.2010. 07564.x

Pihlaja, R., Koistinaho, J., Kauppinen, R., Sandholm, J., Tanila, H., and Koistinaho, M. (2011). Multiple cellular and molecular mechanisms are involved in human Abeta clearance by transplanted adult astrocytes. Glia 59, 1643-1657. doi: 10.1002/glia.21212 
Pinazo-Duran, M. D., Zanon-Moreno, V., Garcia-Medina, J. J., and GallegoPinazo, R. (2013). Evaluation of presumptive biomarkers of oxidative stress, immune response and apoptosis in primary open-angle glaucoma. Curr. Opin. Pharmacol. 13, 98-107. doi: 10.1016/j.coph.2012.10.007

Qiu, T., Liu, Q., Chen, Y. X., Zhao, Y. F., and Li, Y. M. (2015). A $\beta 42$ and A $\beta 40$ : similarities and differences. J. Pept. Sci. 21, 522-529. doi: 10.1002/psc.2789

Quigley, H. A., and Broman, A. T. (2006). The number of people with glaucoma worldwide in 2010 and 2020. Br. J. Ophthalmol. 90, 262-267. doi: 10.1136/bjo.2005.081224

Quigley, H. A., Dunkelberger, G. R., and Green, W. R. (1988). Chronic human glaucoma causing selectively greater loss of large optic nerve fibers. Ophthalmology 95, 357-363. doi: 10.1016/S0161-6420(88)33176-3

Ransohoff, R. M., and Cardona, A. E. (2010). The myeloid cells of the central nervous system parenchyma. Nature 468, 253-262. doi: 10.1038/nature09615

Ransohoff, R. M., and El Khoury, J. (2015). Microglia in health and disease. Cold Spring Harb. Perspect. Biol. 8:a020560. doi: 10.1101/cshperspect.a020560

Ratnayaka, J. A., Serpell, L. C., and Lotery, A. J. (2015). Dementia of the eye: the role of amyloid beta in retinal degeneration. Eye (Lond). 29, 1013-1026. doi: 10.1038/eye.2015.100

Ritzel, R. M., Patel, A. R., Pan, S., Crapser, J., Hammond, M., Jellison, E., et al. (2015). Age- and location-related changes in microglial function. Neurobiol. Aging 36, 2153-2163. doi: 10.1016/j.neurobiolaging.2015.02.016

Rogers, J. T., Morganti, J. M., Bachstetter, A. D., Hudson, C. E., Peters, M. M., Grimmig, B. A., et al. (2011). CX3CR1 deficiency leads to impairment of hippocampal cognitive function and synaptic plasticity. J. Neurosci. 31, 16241-16250. doi: 10.1523/JNEUROSCI.3667-11.2011

Rojas, B., Gallego, B. I., Ramírez, A. I., Salazar, J. J., de Hoz, R., ValienteSoriano, F. J., et al. (2014). Microglia in mouse retina contralateral to experimental glaucoma exhibit multiple signs of activation in all retinal layers. J. Neuroinflammat. 11:133. doi: 10.1186/1742-2094-11-133

Salobrar-Garcia, E., Garcia, Y., Lostao, C., Jañez, L., de Hoz, R., Rojas, B., et al. (2016a). Maculopapillary analysis in the posterior pole in patients with mild Alzheimer's disease. Acta Ophthalmol. doi: 10.1111/j.1755-3768.2016.0372

Salobrar-Garcia, E., Hoyas, I., Leal, M., de Hoz, R., Rojas, B., Ramirez, A. I., et al. (2015). Analysis of retinal peripapillary segmentation in early Alzheimer's disease patients. Biomed. Res. Int. 2015:636548. doi: 10.1155/2015/636548

Salobrar-Garcia, E., Leal, M., Hoyas, I., Salazar, J. J., Ramirez, A. I., de Hoz, R., et al. (2016b). Early changes in mild Alzheimer's disease in the neuroretinal rim segmentation. Acta Ophthalmol. doi: 10.1111/j.1755-3768.2016.0449

Salobrar-García, E., Ramírez, A. I., de Hoz, R., Rojas, P., Salazar, J. J., Rojas, B., et al. (2016c). "Ocular manifestations of dementia: the eye and its role in the diagnosis and monitoring, Chapter 15" in Update on Dementia, ed D. Moretti (InTech). doi: 10.5772/64490

Satue, M., Rodrigo, M. J., Obis, J., Vilades, E., Gracia, H., Otin, S., et al. (2017). Evaluation of progressive visual dysfunction and retinal degeneration in patients with Parkinson's disease. Invest. Ophthalmol. Vis. Sci. 58, 1151-1157. doi: 10.1167/iovs.16-20460

Schafer, D. P., Lehrman, E. K., Kautzman, A. G., Koyama, R., Mardinly, A. R., Yamasaki, R., et al. (2012). Microglia sculpt postnatal neural circuits in an activity and complement-dependent manner. Neuron 74, 691-705. doi: 10.1016/j.neuron.2012.03.026

Schapansky, J., Nardozzi, J. D., and LaVoie, M. J. (2015). The complex relationships between microglia, alpha-synuclein, and LRRK2 in Parkinson's disease. Neuroscience 302, 74-88. doi: 10.1016/j.neuroscience.2014. 09.049

Schlamp, C. L., Li, Y., Dietz, J. A., Janssen, K. T., and Nickells, R. W. (2006). Progressive ganglion cell loss and optic nerve degeneration in DBA/2J mice is variable and asymmetric. BMC Neurosci. 7:66. doi: 10.1186/1471-2202-7-66

Selkoe, D. J. (2004). Cell biology of protein misfolding: the examples of Alzheimer's and Parkinson's diseases. Nat. Cell Biol. 6, 1054-1061. doi: $10.1038 /$ ncb1104-1054

Selkoe, D. J. (2008). Soluble oligomers of the amyloid beta-protein impair synaptic plasticity and behavior. Behav. Brain Res. 192, 106-113. doi: 10.1016/j.bbr.2008.02.016

Shareef, S., Sawada, A., and Neufeld, A. H. (1999). Isoforms of nitric oxide synthase in the optic nerves of rat eyes with chronic moderately elevated intraocular pressure. Invest. Ophthalmol. Vis. Sci. 40, 2884-2891.
Sharma, S., and Lipincott, W. (2017). Biomarkers in Alzheimer's disease-recent update. Curr. Alzheimer Res. doi: 10.2174/1567205014666170220141822. [Epub ahead of print].

Sheedy, F. J., Grebe, A., Rayner, K. J., Kalantari, P., Ramkhelawon, B., Carpenter, S. B., et al. (2013). CD36 coordinates NLRP3 inflammasome activation by facilitating intracellular nucleation of soluble ligands into particulate ligands in sterile inflammation. Nat. Immunol. 14, 812-820. doi: 10.1038/ni. 2639

Sheridan, G. K., and Murphy, K. J. (2013). Neuron-glia crosstalk in health and disease: fractalkine and CX3CR1 take centre stage. Open Biol. 3:130181. doi: 10.1098/rsob.130181

Simard, A. R., Soulet, D., Gowing, G., Julien, J. P., and Rivest, S. (2006). Bone marrow-derived microglia play a critical role in restricting senile plaque formation in Alzheimer's disease. Neuron 49, 489-502. doi: 10.1016/j.neuron.2006.01.022

Sofroniew, M., and Vinters, H. (2010). Astrocytes: biology and pathology. Acta Neuropathol. 119, 7-35. doi: 10.1007/s00401-009-0619-8

Solano, S. M., Miller, D. W., Augood, S. J., Young, A. B., and Penney, J. B. Jr. (2000). Expression of $\alpha$-synuclein, parkin, and ubiquitin carboxy-terminal hydrolase L1 mRNA in human brain: genes associated with familial Parkinson's disease. Ann. Neurol. 47, 201-210. doi: 10.1002/1531-8249(200002)47:2<201::AIDANA10>3.0.CO;2-F

Southam, K. A., Vincent, A. J., and Small, D. H. (2016). Do Microglia default on network maintenance in Alzheimer's disease? J. Alzheimers Dis. 51, 657-669. doi: 10.3233/JAD-151075

Stasi, K., Nagel, D., Yang, X., Wang, R. F., Ren, L., Podos, S. M., et al. (2006). Complement component 1Q (C1Q) upregulation in retina of murine, primate, and human glaucomatous eyes. Invest. Ophthalmol. Vis. Sci. 47, 1024-1029. doi: 10.1167/iovs.05-0830

Steele, M. R., Inman, D. M., Sappington, R. R., Golestaneh, N., Marsh-Armstrong, N., Calkins, D., et al. (2005). Whole retinal microarray analysis of DBA/2J mice: a model for glaucoma. Invest. Ophthalmol. Vis. Sci. 46, 48. doi: 10.1167/iovs. 05-0865

Stefanova, N., Klimaschewski, L., Poewe, W., Wenning, G. K., and Reindl, M. (2001). Glial cell death induced by overexpression of alpha-synuclein. J. Neurosci. Res. 65, 432-438. doi: 10.1002/jnr.1171

Stemplewitz, B., Keseru, M., Bittersohl, D., Buhmann, C., Skevas, C., Richard, G., et al. (2015). Scanning laser polarimetry and spectral domain optical coherence tomography for the detection of retinal changes in Parkinson's disease. Acta Ophthalmol. 93, e672-e677. doi: 10.1111/aos.12764

Stewart, C. R., Stuart, L. M., Wilkinson, K., van Gils, J. M., Deng, J., Halle, A., et al. (2010). CD36 ligands promote sterile inflammation through assembly of a Toll-like receptor 4 and 6 heterodimer. Nat. Immunol. 11, 155-161. doi: 10.1038/ni.1836

Streit, W. J., Conde, J. R., Fendrick, S. E., Flanary, B. E., and Mariani, C. L. (2005). Role of microglia in the central nervous system's immune response. Neurol. Res. 27, 685-691. doi: 10.1179/016164105X49463

Streit, W. J., Mrak, R. E., and Griffin, W. S. (2004). Microglia and neuroinflammation: a pathological perspective. J. Neuroinflammat. 1:14. doi: 10.1186/1742-2094-1-14

Streit, W. J., Walter, S. A., and Pennell, N. A. (1999). Reactive microgliosis. Progr. Neurobiol. 57, 563-581. doi: 10.1016/S0301-0082(98)00069-0

Stutz, B., da Conceicao, F. S., Santos, L. E., Cadilhe, D. V., Fleming, R. L., Acquarone, M., et al. (2014). Murine dopaminergic Muller cells restore motor function in a model of Parkinson's disease. J. Neurochem. 128, 829-840. doi: 10.1111/jnc. 12475

Suh, H.-S., Zhao, M.-L., Derico, L., Choi, N., and Lee, S. C. (2013). Insulinlike growth factor 1 and 2 (IGF1, IGF2) expression in human microglia: differential regulation by inflammatory mediators. J. Neuroinflammat. 10:805. doi: 10.1186/1742-2094-10-37

Surgucheva, I., McMahan, B., Ahmed, F., Tomarev, S., Wax, M. B., and Surguchov, A. (2002). Synucleins in glaucoma: implication of gamma-synuclein in glaucomatous alterations in the optic nerve. J. Neurosci. Res. 68, 97-106. doi: 10.1002/jnr.10198

Surguchov, A., McMahan, B., Masliah, E., and Surgucheva, I. (2001). Synucleins in ocular tissues. J. Neurosci. Res. 65, 68-77. doi: 10.1002/jnr.1129

Takeuchi, A., Irizarry, M. C., Duff, K., Saido, T. C., Hsiao Ashe, K., Hasegawa, M., et al. (2000). Age-related amyloid beta deposition in transgenic mice 
overexpressing both Alzheimer mutant presenilin 1 and amyloid beta precursor protein Swedish mutant is not associated with global neuronal loss. Am. J. Pathol. 157, 331-339. doi: 10.1016/S0002-9440(10)64544-0

Tang, Y., and Le, W. (2016). Differential roles of M1 and M2 microglia in neurodegenerative diseases. Mol. Neurobiol. 53, 1181-1194. doi: 10.1007/s 12035-014-9070-5

Tatton, W. G., Kwan, M. M., Verrier, M. C., Seniuk, N. A., and Theriault, E. (1990). MPTP produces reversible disappearance of tyrosine hydroxylase-containing retinal amacrine cells. Brain Res. 527, 21-31. doi: 10.1016/0006-8993(90)91056-M

Taylor, P. R., Martinez-Pomares, L., Stacey, M., Lin, H., Brown, G. D., and Gordon, S. (2005). Macrophage receptors and immune recognition. Annu. Rev. Immunol. 23, 901-944. doi: 10.1146/annurev.immunol.23.021704. 115816

Taylor, S., Calder, C. J., Albon, J., Erichsen, J. T., Boulton, M. E., and Morgan, J. E. (2011). Involvement of the CD200 receptor complex in microglia activation in experimental glaucoma. Exp. Eye Res. 92, 338-343. doi: 10.1016/j.exer.2011.01.012

Terwel, D., Steffensen, K. R., Verghese, P. B., Kummer, M. P., Gustafsson, J. A., Holtzman, D. M., et al. (2011). Critical role of astroglial apolipoprotein $\mathrm{E}$ and liver X receptor-alpha expression for microglial Abeta phagocytosis. J. Neurosci. 31, 7049-7059. doi: 10.1523/JNEUROSCI.6546-1 0.2011

Tezel, G. (2009). the Fourth ARVO/Pfizer Ophthalmics Research Institute Conference,Working Group. The role of glia, mitochondria, and the immune system in glaucoma. Invest. Ophthalmol. Vis. Sci. 50, 1001-1012. doi: $10.1167 /$ iovs.08-2717

Tezel, G. (2013). Immune regulation toward immunomodulation for neuroprotection in glaucoma. Curr. Opin. Pharmacol. 13, 23-31. doi: 10.1016/j.coph.2012.09.013

Tezel, G., Li, L. Y., Patil, R. V., and Wax, M. B. (2001). TNF- $\alpha$ and TNF- $\alpha$ receptor1 in the retina of normal and glaucomatous eyes. Invest. Ophthalmol. Vis. Sci. 42, 1787-1794.

Tezel, G., Yang, J., and Wax, M. B. (2004). Heat shock proteins, immunity and glaucoma. Brain Res. Bull. 62, 473-480. doi: 10.1016/S0361-9230(03)00074-1

Tofaris, G. K., Razzaq, A., Ghetti, B., Lilley, K. S., and Spillantini, M. G. (2003). Ubiquitination of alpha-synuclein in Lewy bodies is a pathological event not associated with impairment of proteasome function. J. Biol. Chem. 278, 44405-44411. doi: 10.1074/jbc.M308041200

Tsai, C. S., Ritch, R., Schwartz, B., Lee, S. S., Miller, N. R., Chi, T., et al. (1991). Optic nerve head and nerve fiber layer in Alzheimer's disease. Arch. Ophthalmol. 109, 199-204. doi: 10.1001/archopht.1991.01080020045040

Tsai, Y., Lu, B., Ljubimov, A. V., Girman, S., Ross-Cisneros, F. N., Sadun, A. A., et al. (2014). Ocular changes in TgF344-AD rat model of Alzheimer's disease. Invest. Ophthalmol. Vis. Sci. 55, 523-534. doi: 10.1167/iovs.1 3-12888

Udeochu, J. C., Shea, J. M., and Villeda, S. A. (2016). Microglia communication: parallels between aging and Alzheimer's disease. Clin. Exp. Neuroimmunol. 7, 114-125. doi: 10.1111/cen3.12307

Uttara, B., Singh, A. V., Zamboni, P., and Mahajan, R. T. (2009). Oxidative stress and neurodegenerative diseases: a review of upstream and downstream antioxidant therapeutic options. Curr. Neuropharmacol. 7, 65-74. doi: $10.2174 / 157015909787602823$

van Boxel-Dezaire, A. H., Rani, M. R., and Stark, G. R. (2006). Complex modulation of cell type-specific signaling in response to type I interferons. Immunity 25, 361-372. doi: 10.1016/j.immuni.2006.08.014

Varnum, M. M., and Ikezu, T. (2012). The classification of microglial activation phenotypes on neurodegeneration and regeneration in Alzheimer's disease brain. Arch. Immunol. Ther. Exp. 60, 251-266. doi: 10.1007/s00005-012-0181-2

Veerhuis, R. (2011). Histological and direct evidence for the role of complement in the neuroinflammation of AD. Curr. Alzheimer Res. 8, 34-58. doi: 10.2174/156720511794604589

Verkhratsky, A., and Butt, A. M. (2013). Glial Physiology and Pathophysiology. Oxford: Wiley-Blackwell-John Wiley \& Sons.

Verkhratsky, A., Parpura, V., Pekna, M., Pekny, M., and Sofroniew, M. (2014). Glia in the pathogenesis of neurodegenerative diseases. Biochem. Soc. Trans. 42, 1291-1301. doi: 10.1042/BST20140107
Vidal, L., Díaz, F., Villena, A., Moreno, M., Campos, J. G., and de Vargas, I. P. (2006). Nitric oxide synthase in retina and optic nerve head of rat with increased intraocular pressure and effect of timolol. Brain Res. Bull. 70, 406-413. doi: 10.1016/j.brainresbull.2006.07.009

Vivekanantham, S., Shah, S., Dewji, R., Dewji, A., Khatri, C., and Ologunde, R. (2015). Neuroinflammation in Parkinson's disease: role in neurodegeneration and tissue repair. Int. J. Neurosci. 125, 717-725. doi: 10.3109/00207454.2014. 982795

Vodovotz, Y., Lucia, M. S., Flanders, K. C., Chesler, L., Xie, Q. W., Smith, T. W., et al. (1996). Inducible nitric oxide synthase in tangle-bearing neurons of patients with Alzheimer's disease. J. Exp. Med. 184, 1425-1433. doi: $10.1084 /$ jem.184.4.1425

Wang, K., Peng, B., and Lin, B. (2014). Fractalkine receptor regulates microglial neurotoxicity in an experimental mouse glaucoma model. Glia 62, 1943-1954 doi: 10 1002/glia 22715

Wang, J., Jackson, M. F., and Xie, Y. F. (2016). Glia and TRPM2 channels in plasticity of central nervous system and Alzheimer's diseases. Neural Plast. 2016:1680905. doi: 10.1155/2016/1680905

Wang, Q., Liu, Y., and Zhou, J. (2015). Neuroinflammation in Parkinson's disease and its potential as therapeutic target. Transl. Neurodegener. 4:19-015-0042-0. eCollection 2015. doi: 10.1186/s40035-015-0042-0

Wang, X. J., Zhang, S., Yan, Z. Q., Zhao, Y. X., Zhou, H. Y., Wang, Y., et al. (2011). Impaired CD200-CD200R-mediated microglia silencing enhances midbrain dopaminergic neurodegeneration: roles of aging, superoxide, NADPH oxidase, and p38 MAPK. Free Radic. Biol. Med. 50, 1094-1106. doi: 10.1016/j.freeradbiomed.2011.01.032

Wax, M. B., Tezel, G., and Edward, P. D. (1998). Clinical and ocular histopathological findings in a patient with normal-pressure glaucoma. Arch. Ophthalmol. 116, 993-1001. doi: 10.1001/archopht.116.8.993

Wax, M. B., Tezel, G., Kawase, K., and Kitazawa, Y. (2001). Serum autoantibodies to heat shock proteins in glaucoma patients from Japan and the United States. Ophthalmology 108, 296-302. doi: 10.1016/S0161-6420(00)00525-X

Williams, E. A., McGuone, D., Frosch, M. P., Hyman, B. T., Laver, N., and Stemmer-Rachamimov, A. (2017). Absence of Alzheimer disease neuropathologic changes in eyes of subjects with Alzheimer disease. J. Neuropathol. Exp. Neurol. 76, 376-383. doi: 10.1093/jnen/nlx020

Williams, P. A., Marsh-Armstrong, N., Howell, G. R. (2017). Lasker/IRRF initiative on astrocytes and glaucomatous neurodegeneration participants. Neuroinflammation in glaucoma: a new opportunity. Exp. Eye Res. 157, 20-27. doi: 10.1016/j.exer.2017.02.014

Wostyn, P., Audenaert, K., and De Deyn, P. P. (2010). Alzheimer's disease: cerebral glaucoma? Med. Hypotheses 74, 973-977. doi: 10.1016/j.mehy.2009.12.019

Wu, L., Vadakkan, K. I., and Zhuo, M. (2007). ATP-induced chemotaxis of microglial processes requires $\mathrm{P} 2 \mathrm{Y}$ receptor-activated initiation of outward potassium currents. Glia 55, 810-821. doi: 10.1002/glia.20500

Wyss-Coray, T. (2006). Inflammation in Alzheimer disease: driving force, bystander or beneficial response? Nat. Med. 12, 1005-1015. doi: $10.1038 / \mathrm{nm} 1484$

$\mathrm{Xu}, \mathrm{L}$., He, D., and Bai, Y. (2016). Microglia-mediated inflammation and neurodegenerative disease. Mol. Neurobiol. 53, 6709-6715. doi: 10.1007/s1 2035-015-9593-4

Yan, S. D., Chen, X., Fu, J., Chen, M., Zhu, H., Roher, A., et al. (1996). RAGE and amyloid-beta peptide neurotoxicity in Alzheimer's disease. Nature 382, 685-691.

Yan, Z., Gibson, S. A., Buckley, J. A., Qin, H., and Benveniste, E. N. (2016). Role of the JAK/STAT signaling pathway in regulation of innate immunity in neuroinflammatory diseases. Clin. Immunol. doi: 10.1016/j.clim.2016.09.014. [Epub ahead of print].

Yang, J., Patil, R. V., Yu, H., Gordon, M., and Wax, M. B. (2001a). T cell subsets and sIL-2R/IL-2 levels in patients with glaucoma. Am. J. Ophthalmol. 131, 421-426. doi: 10.1016/S0002-9394(00)00862-X

Yang, J., Yang, P., Tezel, G., Patil, R. V., Hernandez, M. R., and Wax, M. B. (2001b). Induction of HLA-DR expression in human lamina cribrosa astrocytes by cytokines and simulated ischemia. Invest. Ophthalmol. Vis. Sci. 42, 365-371.

Yu, J. G., Feng, Y. F., Xiang, Y., Huang, J. H., Savini, G., Parisi, V., et al. (2014). Retinal nerve fiber layer thickness changes in Parkinson disease: a meta-analysis. PLoS ONE 9:e85718. doi: 10.1371/journal.pone.0085718 
Yuan, L., and Neufeld, A. H. (2001). Activated microglia in the human glaucomatous optic nerve head. J. Neurosci. Res. 64, 523-532. doi: 10.1002/jnr.1104

Yucel, Y. H., Zhang, Q., Weinreb, R. N., Kaufman, P. L., and Gupta, N. (2003). Effects of retinal ganglion cell loss on magno-, parvo-, koniocellular pathways in the lateral geniculate nucleus and visual cortex in glaucoma. Prog. Retin. Eye Res. 22, 465-481. doi: 10.1016/S1350-9462(03)00026-0

Yuruker, V., Naziroglu, M., and Senol, N. (2015). Reduction in traumatic brain injury-induced oxidative stress, apoptosis, and calcium entry in rat hippocampus by melatonin: possible involvement of TRPM2 channels. Metab. Brain Dis. 30, 223-231. doi: 10.1007/s11011-014-9623-3

Zecca, L., Wilms, H., Geick, S., Claasen, J. H., Brandenburg, L. O., Holzknecht, C., et al. (2008). Human neuromelanin induces neuroinflammation and neurodegeneration in the rat substantia nigra: implications for Parkinson's disease. Acta Neuropathol. 116, 47-55. doi: 10.1007/s00401-008-0361-7

Zhang, Q. S., Heng, Y., Yuan, Y. H., and Chen, N. H. (2017). Pathological alpha-synuclein exacerbates the progression of Parkinson's disease through microglial activation. Toxicol Lett 265, 30-37. doi: 10.1016/j.toxlet.2016. 11.002
Zhang, S., Wang, X.-J., Tian, L.-P., Pan, J., Lu, G.-Q., Zhang, Y.-J., et al. (2011). CD200-CD200R dysfunction exacerbates microglial activation and dopaminergic neurodegeneration in a rat model of Parkinson's disease. J. Neuroinflammat. 8:154. doi: 10.1186/1742-2094-8-154

Zhou, X., He, X., and Ren, Y. (2014). Function of microglia and macrophages in secondary damage after spinal cord injury. Neural Regen. Res 9, 1787-1795. doi: $10.4103 / 1673-5374.143423$

Conflict of Interest Statement: The authors declare that the research was conducted in the absence of any commercial or financial relationships that could be construed as a potential conflict of interest.

Copyright $\odot 2017$ Ramirez, de Hoz, Salobrar-Garcia, Salazar, Rojas, Ajoy, LópezCuenca, Rojas, Triviño and Ramírez. This is an open-access article distributed under the terms of the Creative Commons Attribution License (CC BY). The use, distribution or reproduction in other forums is permitted, provided the original author(s) or licensor are credited and that the original publication in this journal is cited, in accordance with accepted academic practice. No use, distribution or reproduction is permitted which does not comply with these terms. 